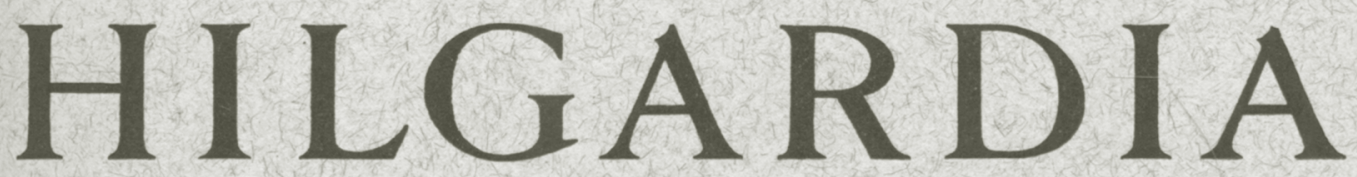

A Journal of Agricultural Science Published by the California Agricultural Experiment Station

\title{
BIOLOGY OF THE NAVEL ORANGEWORM,
} PARAMYELOIS TRANSITELLA (WALKER), ON ALMONDS AND WALNUTS IN NORTHERN CALIFORNIA

WILLAM H. WADE 


\section{CONTENTS}

INTRODUCTION . . . . . . . • . • . . 129

HISTORICAL REVIEW * . . . . . . . . . . . . 129

DESCRIPTION . . . . . . . . . . . . . . . 131

GEOGRAPHICAL DISTRIBUTION . . . . . . . 136

HOST RANGE *. . . . . . . . . . . 138

EXPERIMENTAL METHODS . . . . . . . . . . 138

Bait Pans . . . . . . . . . . . 138

Bait Traps . . . . . . . . . . . . 139

Nut Samples . . . . . . . . . . . . . 139

Maintenance of Stock Cultures in the Laboratory . . . . 139

Mating Cages (Indoor and Outdoor) . . . . . . . . 139

Oviposition Chambers . . . . . . . . . . . 140

Individual Rearing Cages . . . . . . . . . . . . 140

Constant Relative Humidity Chambers . . . . . . 140

Constant Temperature Cabinets . . . . . . . . . 140

Longevity Vials . . . . . . . . . . . . . 140

Mounting Technique . . . . . . . . . . . 141

METHODS OF INSTAR DETERMINATION . . . . . 141

Head Capsules . . . . . . . . . . . . . . 141

Crotchets . . . . . . . . . . . . . . 142

MATING . . . ............. . . 145

Laboratory Investigations . . . . . . . . . . . 145

Outdoor Investigations . . . . . . . . . . . 145

OVIPOSITION . . . . . . . . . . . . . . 147

LABORATORY REARINGS * . . . . . . . . . . 148

Incubation Period . . . . . . . . . . . . . 148

Larval Instars . . . . . . . . . . . . . . . 150

Duration of Development . . . . . . . . . . . 151

Length of Adult Life . . . . . . . . . . . . . 154

Pupal Weights and Lengths. . . . . . . . . 154

FIELD BIOLOGY • * • . • • • . . . . . 156

Habits . . . . . . . . . . . . . 156

Activity in Almonds . . . . . . . . . . 157

Activity in Walnuts . . . . . . . . . . . 161

Activity in Figs . . . . . . . . . . . . . . 161

Adult Activity . . . . . . . . . . . . . . 161

NATURE OF INJURY . . . . . . . . . . . . 162

CONTROL . . . . . . . . . . . . . 164

Natural Control ........... . . . . . 164

Chemical Control . . . . . . . . . . . . 166

Cultural Control . . . . . . . . . . . . 167

SUMMARY . . . . . . . . . . . . . . . 167

ACKNOWLEDGMENTS . . . . . . . . . . 169

LITERATURE CITED . . . . . . . . • . . 170 


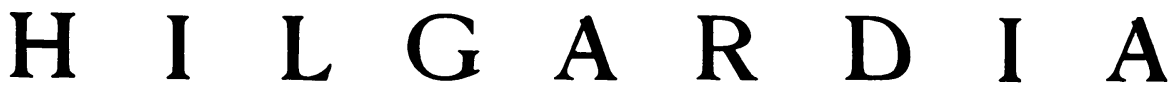

A Journal of Agricultural Science Published by

the California Agricultural Experiment Station

\begin{tabular}{lll}
\hline VoL. 31 & OCTOBER, 1961 & No. 6 \\
\hline
\end{tabular}

\section{BIOLOGY OF THE NAVEL ORANGEWORM, PARAMYELOIS TRANSITELLA (WALKER), ON ALMONDS AND WALNUTS IN NORTHERN CALIFORNIA ${ }^{1}$}

\author{
WILLIAM H. WADE
}

\section{INTRODUCTION}

The navel orangeworm, Paramyelois transitella (Walker), was first observed in the Salt River Valley of Arizona, infesting Washington and Australian navel oranges. Investigations by Glick (1922) ${ }^{3}$ and Lockwood (1931) showed that it was a secondary pest. Nevertheless, California growers became alarmed because of the extensive citrus plantings in this state.

The insect was first observed in southern California in 1942 (Mackie, 1942), and has steadily moved northward until it is now established in many sections of northern California. It breeds readily in mummified fruits and in California has proved to be a serious pest of walnuts and almonds. Armitage (1947) reported it as a pest in walnut packing sheds. Ortega (1950), who conducted his investigations in southern California, observed it as a field and storage pest of walnuts.

Because the navel orangeworm appeared to be a potential pest in northern California, the investigations here reported were undertaken to determine its habits and the ecological factors that influence its behavior and abundance.

\section{HISTORICAL REVIEW}

The navel orangeworm, Paramyelois transitella (Walker), family Phycitidae (Pyralididae), was first described as Myelois venipars (Dyar, 1915) from two specimens, a male from Oaxaca, Mexico, and a female from Hermosillo, Mexico (cotypes U. S. National Museum No. 18208). However, it is possible that it occurred near Phoenix, Arizona, prior to this, for Cockerell (1899) mentioned the presence of a new orangeworm in the area. He gave no description, but stated that it resembled the codling-moth larva, which was not found there. He compared the mandibles of his orangeworm and the codling moth and found them to be quite different.

\footnotetext{
${ }^{1}$ Received for publication April 26, 1961.

${ }^{2}$ Graduate Research Entomologist; Research Assistant (Ph.D. Thesis).

${ }^{3}$ See "Literature Cited" for citations, referred to in the text by author and date.
} 
Mote (1922) reported that on October 4, 1920, the Federal Bureau of Entomology took one adult in a light trap near Tempe, Arizona. This was the first recorded collection of the navel orangeworm in the United States. $\mathrm{H}_{t}$ further noted that the navel orangeworm came into prominence in $1921 . \mathrm{He}$ stated that during July of that year, navel oranges in the Salt River Valley of Arizona were falling in greater abundance than usual, and many of them were infected with a blackrot known as Alternaria citri Ellis and Pierce. A survey of the groves showed that practically all the diseased fruits were infested with caterpillars of the navel orangeworm. Because the disease and the caterpillars were found only in Washington and Australian navel oranges, the larvae were thought to be responsible for the presence of the disease. Mote also called attention to the fact that the Arizona Commission of Agriculture and Horticulture, in a letter, offered California authorities an opportunity to investigate the problem and simultaneously prohibited the movement of Arizona navel oranges into California. This embargo was supplemented by the California authorities with instructions to all quarantine inspectors and guardians to refuse to admit navel oranges from Arizona. A quarantine order was not promulgated, for fear of causing unnecessary injury to the Arizona citrus industry. Mackie and Jacobsen (1930) mentioned that the above order was superseded on March 11, 1927, by Quarantine Circular No. 7, with no changes being made in regard to excluding fruit from California.

At a meeting in March, 1924, that dealt with the association of the navel orangeworm and Alternaria citri, Glick (1925) read a paper expressing the belief that the navel orangeworm was a secondary pest. This belief was sub. stantiated by investigations conducted in the Salt River Valley and the Yuma and Mesa areas by Lockwood of the California State Department of Agriculture and by members of the Arizona State Department of Agriculture. They found that the larvae were confined to "splits," or to oranges that had been injured previously. Further, they increased the host range by reporting infestations in grapefruit, lemon, fig, pear, rotting pomegranates, and all varieties of orange.

Lockwood (1931) stated that eggs were found on the rind, near or in splits or cracks. Eggs, but no live caterpillars, were found on several hundred sound oranges. In only two cases were dead caterpillars encountered, and they had apparently died from inability to penetrate the unblemished rind. Infestation was found to be associated with blackrot.

In December, 1933, Hixson (1934) collected several larvae from a "Jention" (Geniton) apple at Stillwater, Oklahoma, which were reared by him and determined by Heinrich, of the Bureau of Entomology and Plant Quarantine, United States Department of Agriculture, to be Myelois venipars Dyar.

In November, 1942, the navel orangeworm was taken for the first time in California in Orange County. By 1943, the insect was apparently rather widely distributed in southern California, for Armitage (1944) reported that moths were taken repeatedly in traps intended for the oriental fruit moth in Orange, San Bernardino, and Los Angeles counties. (For a fuller historical account of the navel orangeworm, see also Ebeling [1959], p. 346.) 
In 1946, Armitage (1947) stated that some walnut packing houses in southern California were infested with navel orangeworm larvae. The infestation was limited almost entirely to nuts which had been previously infested by codling moth. Similar reports were issued by Keifer (1947) and Ortega (1950), in which they indicated that by 1947 , large numbers of larvae were being found in packing houses in Los Angeles and Ventura counties.

Since its discovery in southern California in 1942, the navel orangeworm has rapidly spread northward. Records received in $1952^{4}$ indicate that by

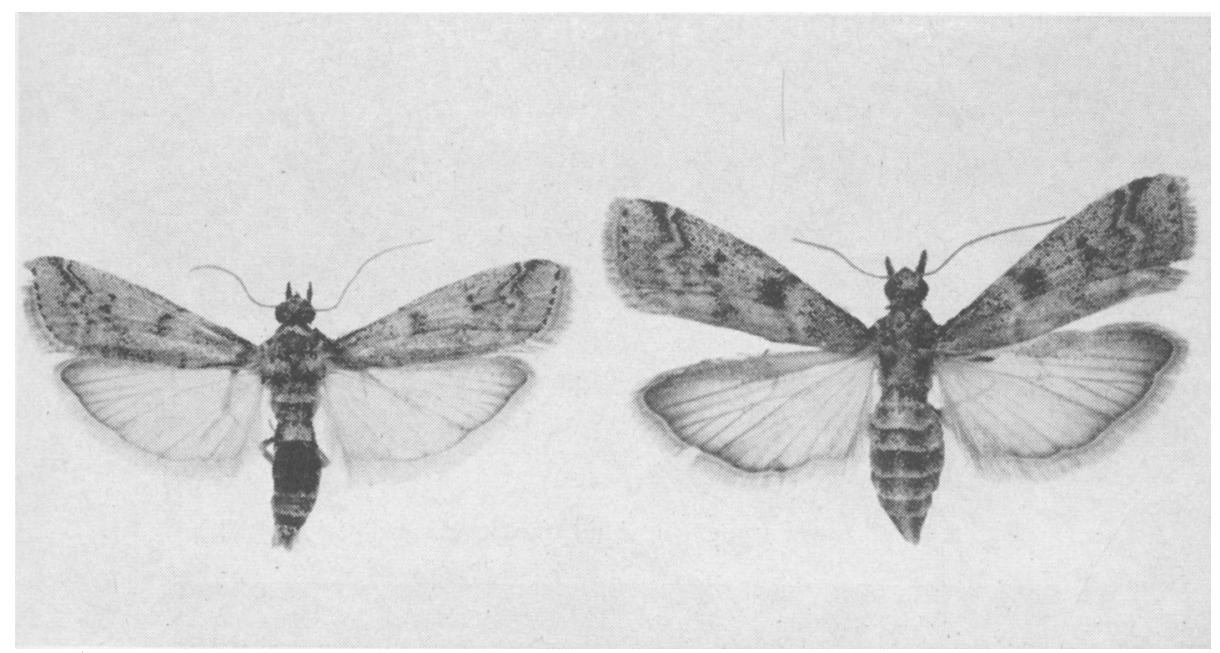

Fig. 1. Adults of the navel orangeworm. Left: Male. Right: Female. $(\times 3$.

1949, infestations were found as far north as Tehama County. At present, the insect occurs in practically all the important fruit- and nut-producing areas in the state.

\section{DESCRIPTION}

Adult. The adults (figs. 1 and 2) are silver gray. The forewings are ornamented with a dark pattern of black, irregularly narrow to broadly wavy lines. The hindwings are uniformly light, darkening at the apex and along the veins. The females are larger than the males.

The wing expanse from wing tip to wing tip of adult males, based on a sample of sixteen individuals, ranged from 19 to $23.5 \mathrm{~mm}$., with a mean of $21.2 \mathrm{~mm} . \pm 1.4 \mathrm{~mm}$. The body length of the males, measuring from the anterior tip of the head to the posterior tip of the abdomen, ranged from 8 to $12 \mathrm{~mm}$., with a mean of $9.7 \mathrm{~mm} . \pm 1.0 \mathrm{~mm}$. The wing expanse of the females, based on a sample of twenty-two individuals, ranged from 18 to $27 \mathrm{~mm}$., with a mean of $22.4 \mathrm{~mm}$. $\pm 2.0 \mathrm{~mm}$., while the body length ranged from 9 to $12.5 \mathrm{~mm}$., with a mean of $10.9 \mathrm{~mm} . \pm 1.0 \mathrm{~mm}$.

Egg. The newly deposited egg (fig. 3 ) is lustrous creamy white, changing in color as incubation progresses to pink and then to reddish orange. The color change is very evident after about twenty-four hours. About forty-eight

\footnotetext{
${ }^{4}$ Letter to the author from H. H. Keifer, August 29, 1952.
} 


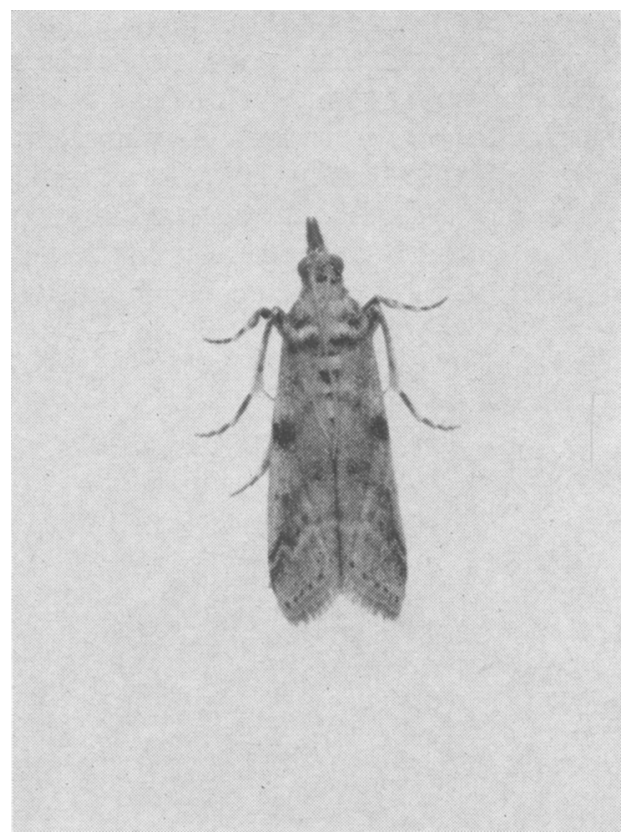

Fig. 2. Adult navel orangeworm in typical resting position. $(\times 3$.

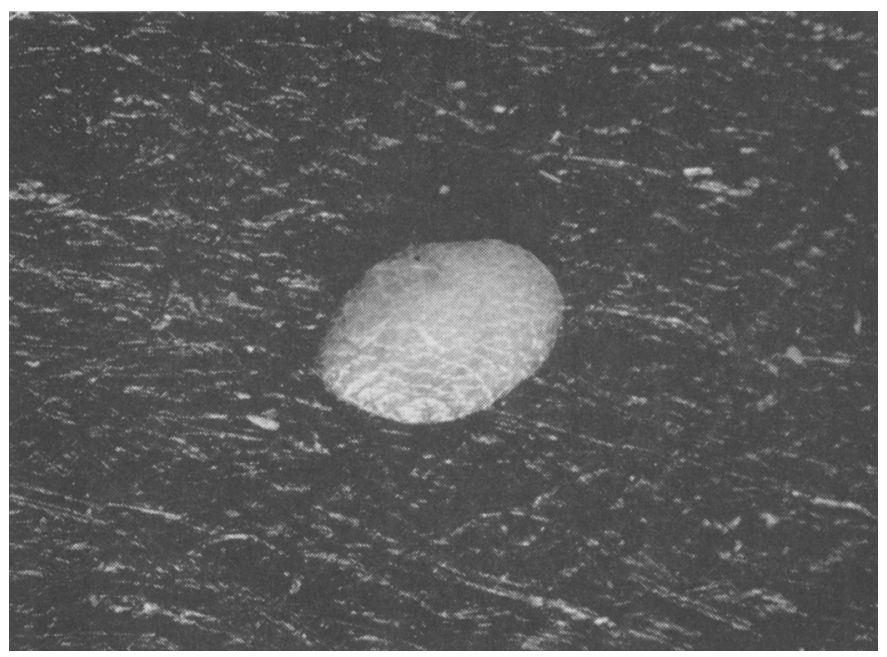

Fig. 3. Egg of the navel orangeworm. $(\times 25$.

hours before hatching, the forming embryo can be seen, and twenty-four hours before hatching, the developed larva with black head is easily distinguished.

The egg is flattened dorsoventrally, is elliptical or oval in outline, and measures from .5 to $1 \mathrm{~mm}$. When viewed under high magnification, the surface of the egg is reticulated, with numerous ridgelike markings. 

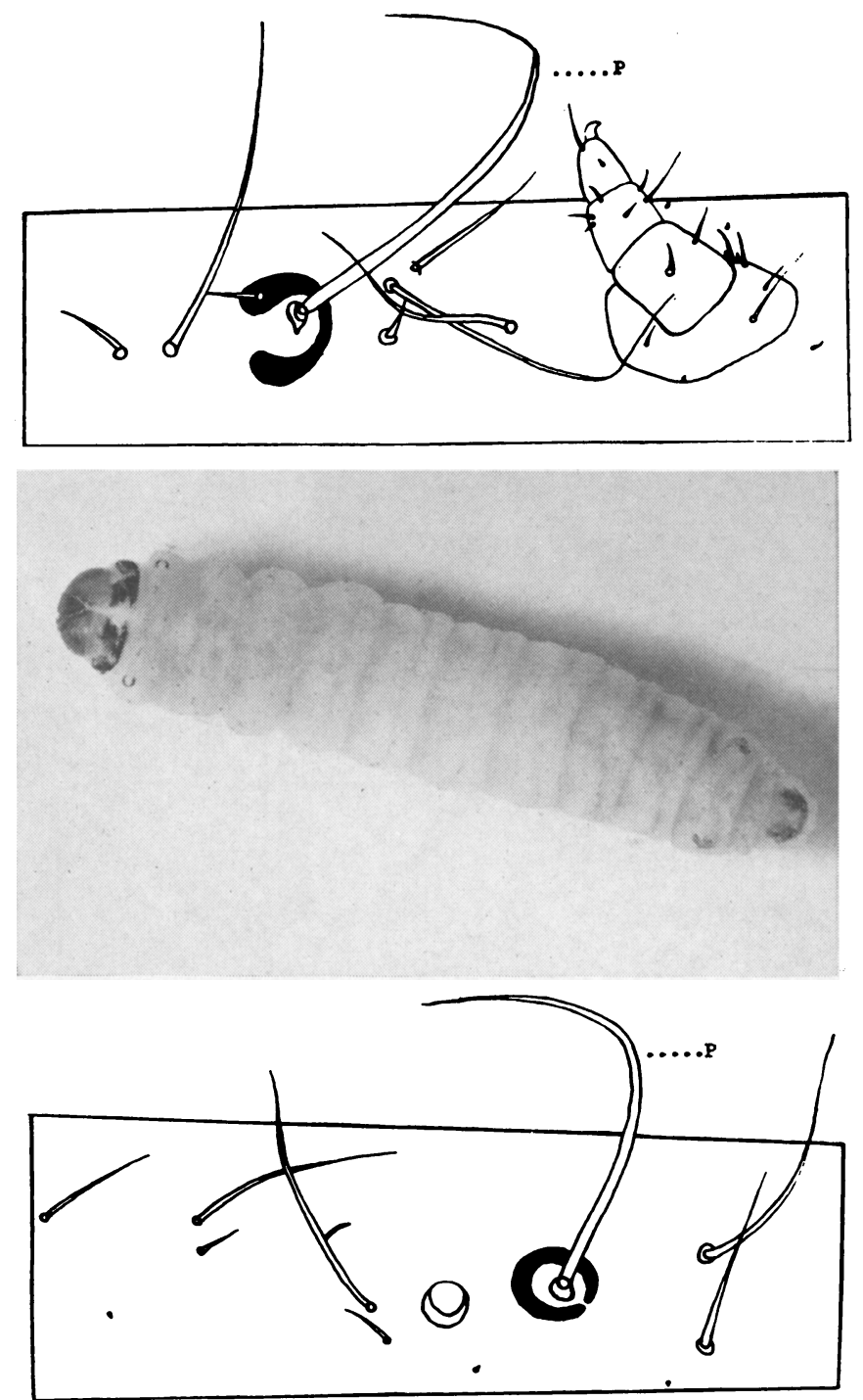

Fig. 4. Top: Typical crescent on mesothoracic segment of fifth-instar larva of the navel orangeworm. $(\times 25$. $)$ Center: Larva, showing characteristic crescents on mesothorax and eighth abdominal segment. $(\times 6$.$) Bottom: Typical crescent on eighth abdominal segment.$ $(\times 25$.

Larva. The larva (fig. 4) is reddish orange upon hatching, the color being the same as that of the mature fertile eggs. This color persists through the first instar. After molting and while in the second instar, the larva ranges from pinkish orange to cream color. In the later instars, as the larva matures, the color is influenced by the nature of its food. Larvae feeding on light foods are lighter in color than those feeding on dark substances. If the food is contaminated with black mold spores, the intestinal traict will appear black. 


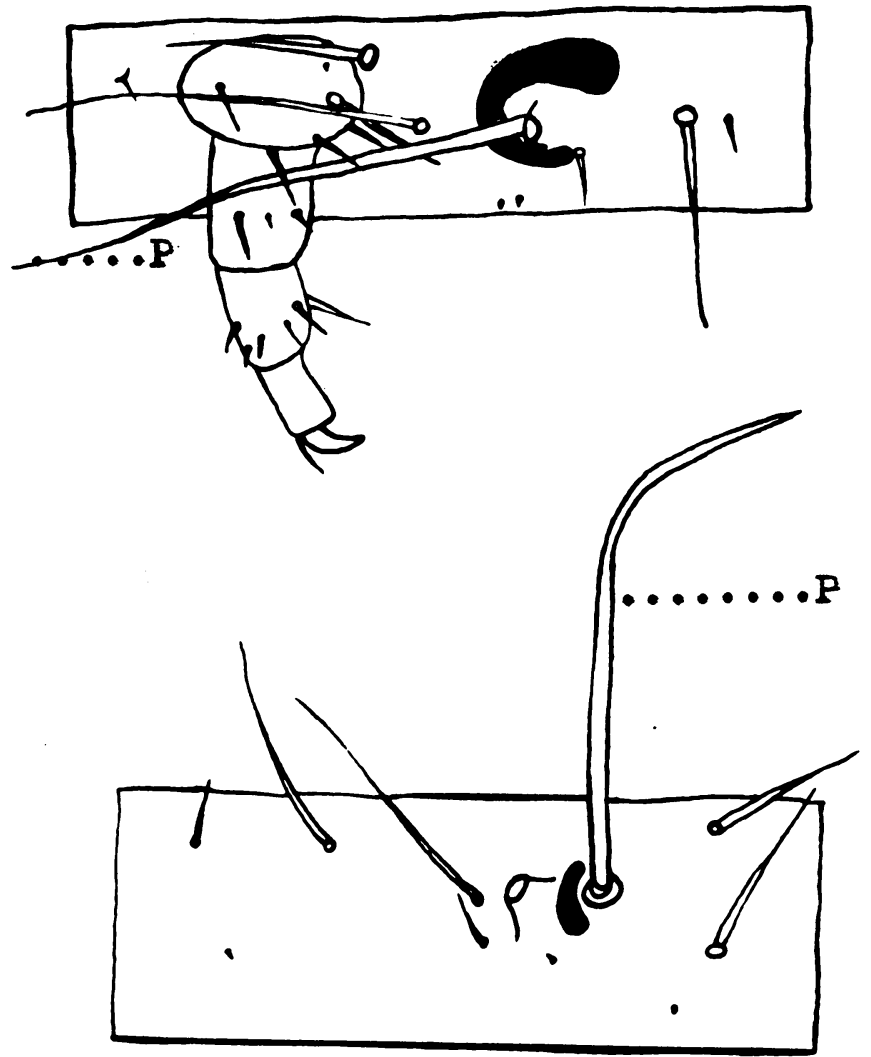

Fig. 5. Typical sclerotized areas at base of seta $P$ in first-instar larva of the navel orangeworm. Top: Mesothoracic segment. Bottom: Eighth abdominal segment. $(\times 215$. $)$
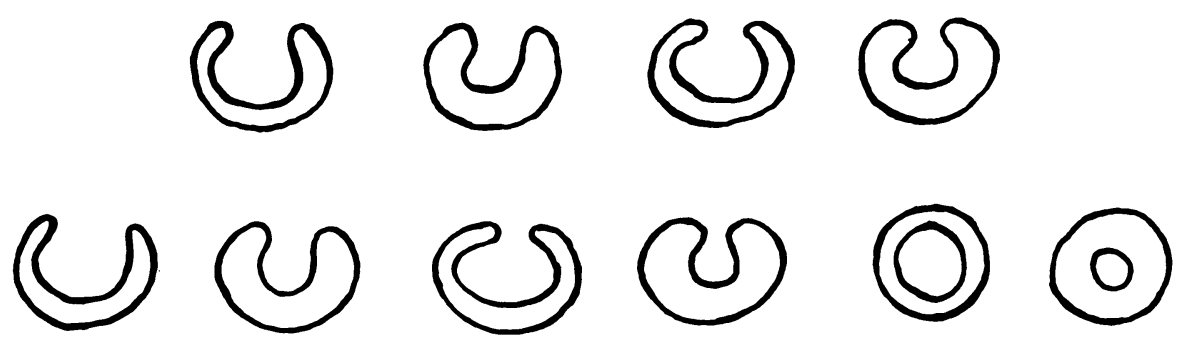

Fig. 6. Variations in sclerotized areas at base of seta $P$ in the navel orangeworm larva. Top: Mesothoracic segment. Bottom: Eighth abdominal segment.

Those having fed on almond meats are cream color, while those reared on walnut meats range from pale to deep pinkish orange. The color tends to be more concentrated at the posterior end. With maturity and the approach of the prepupal stage, the intensity of color decreases. Individuals that develop on orange are orange in color.

The color of the head capsule in all instars is a fairly uniform dark reddish brown, with none to very slight mottling. The color of the tubercles at the 
base of the setae varies in intensity on different larvae, there being more pigment present in some than in others. The reason for this is not understood, but under conditions of high humidity the tubercles are usually much darker.

In all larval instars, the pigmented area about seta $P$ on the mesothorax is somewhat larger and crescent-shapcd, as compared to those on the surrounding setae. The pigmented area around seta $\boldsymbol{P}$ on the eighth abdominal segment is also crescent-shaped, although in some specimens this sclerotized area

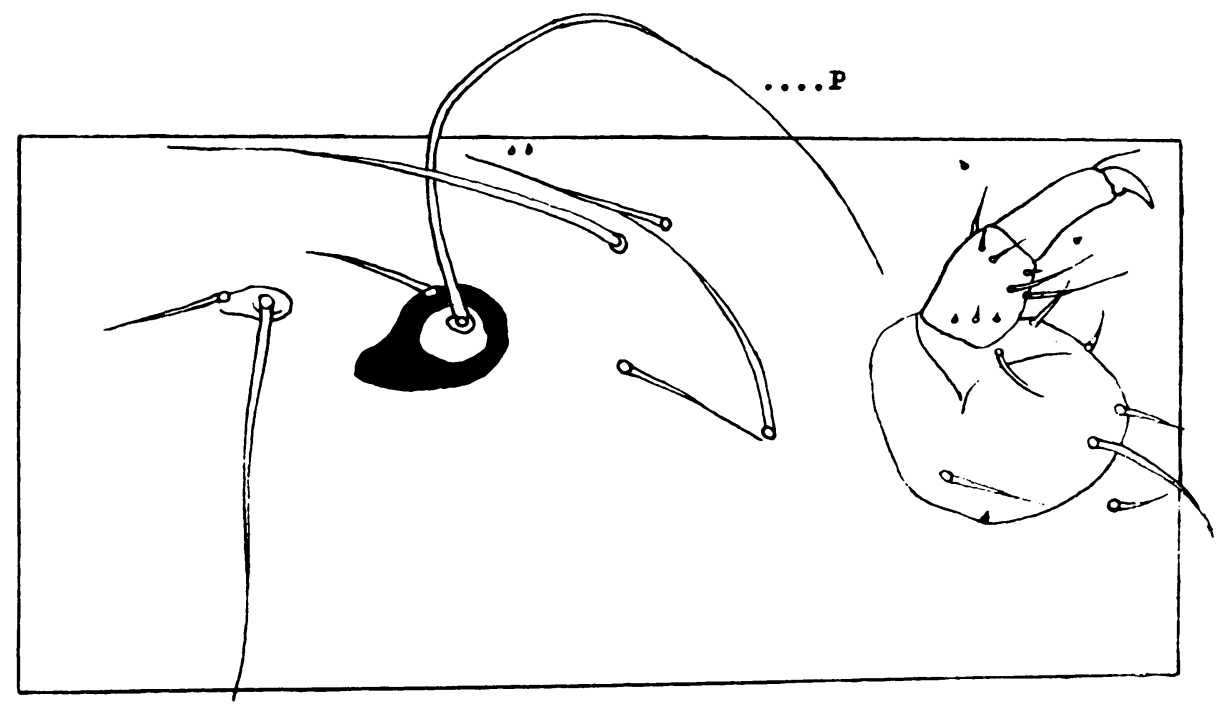

Fig. 7. Typical circle on mesothoracic segment of last-instar larva of the Mediterranean flour moth. $(\times 34$.

may close to form a circle. These characters are illustrated in figures 4 through 6. It should be noted that where the crescents occur, the open area is always to the dorsum. On heavily sclerotized larvae, the erescents are usually closed to form a circle on the eighth abdominal segment.

These characters are useful in separating larvae of the navel orangeworm from those of the related Mediterranean flour moth, Anagasta kïhniella (Zeller), with which it is easily confused. The condition encountered in the Mediterranean flour moth larva is illustrated in figures 7 and 8 . With the Mediterranean flour moth, the pigmented areas surrounding seta $P$ on the mesothorax are always closed to form circles. Those which occur on the eighth abdominal segment are usually closed, although in some cases they may be op€ncd to form crescents. (See also Ebeling [1959], especially pp. 214, 350.)

Pupa. The pupa (fig. 9) is dark brown in color, with the sutures clearly evident. The anterior portion is rounded, while the posterior portion is rather blunt. Genital openings are prominent and are easily observed in both male and female pupae. The pupae range in length from 7.25 to $12 \mathrm{~mm}$., those of the female averaging larger than those of the male. 


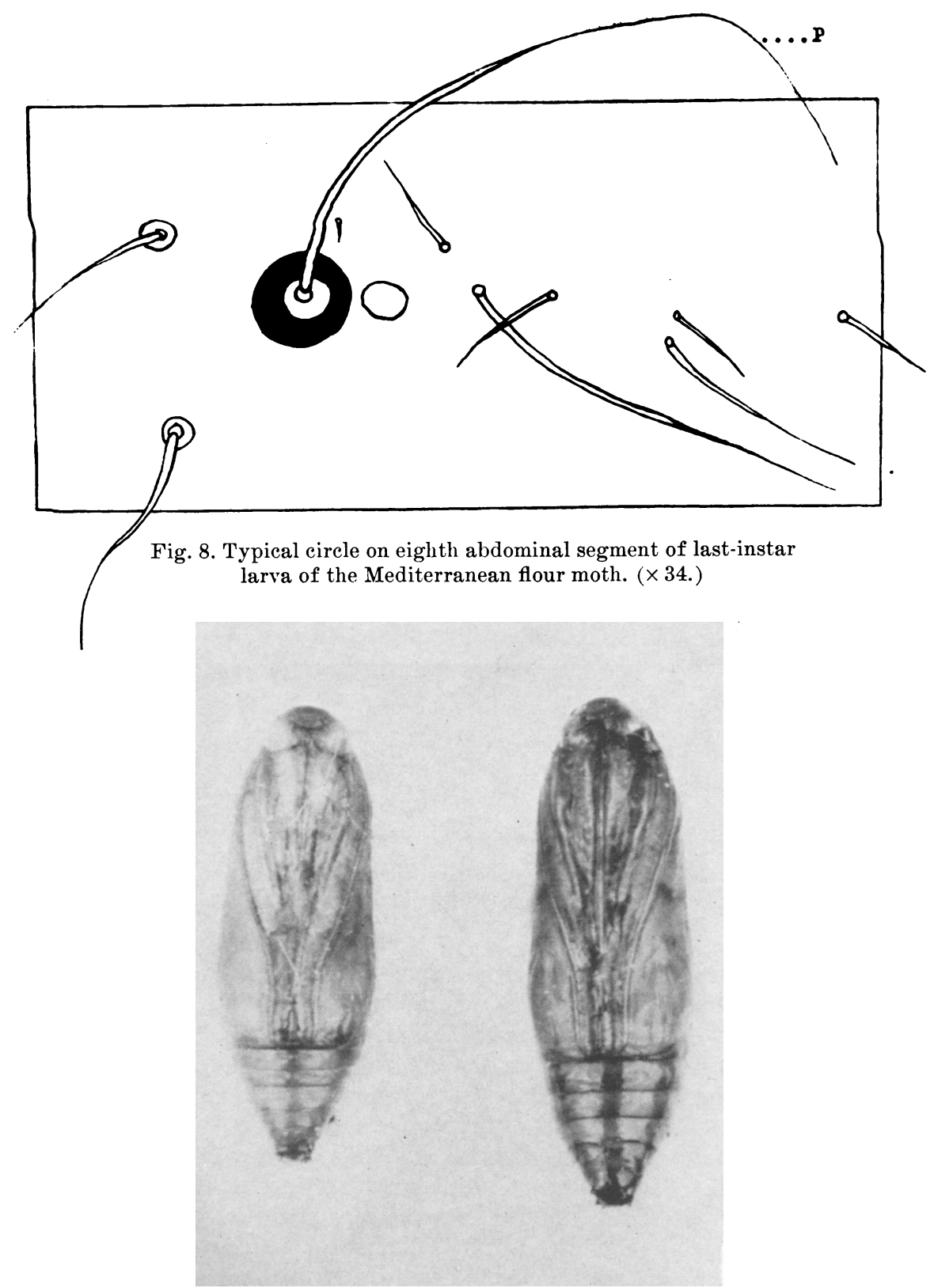

Fig. 9. Pupae of the navel orangeworm. Loft: Male. Right: Female. (×6.)

\section{GEOGRAPHICAL DISTRIBUTION}

The navel orangeworm has been recorded only from Mexico and the United States. The first specimens were described by Dyar (1915) from Oaxaca and Hermosillo, Mexico. The distribution of this insect in the United States is 
discontinuous, but it is rather widely distributed throughout the Southwest. It has been found near Tempe, in the Salt River Valley, and in the Yuma and Mesa areas of Arizona, according to Mote (1922). Hixson (1934) reported the navel orangeworm's occurrence at Stillwater, Oklahoma, and Bissel (1940) noted its presence in Spalding County, central Georgia.

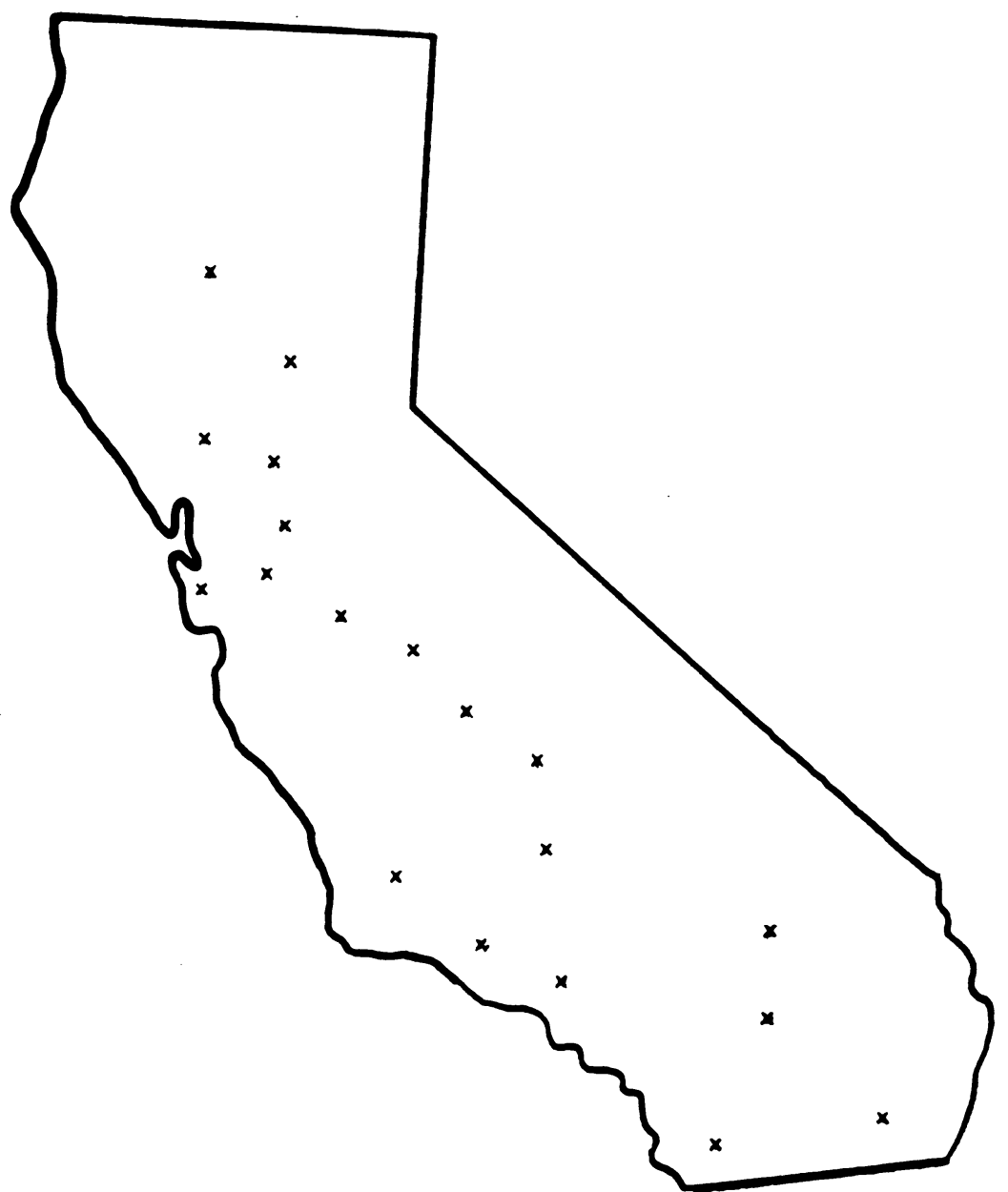

Fig. 10. Distribution of the navel orangeworm in California as of 1950.

It was first found in Orange County, California, in 1942 (Mackie, 1942; Ebeling, 1959). Its spread through 1950 in this state is shown in figure 10, and is listed below by counties in chronological order.

Orange, 1942; Los Angeles, 1943 (per letter from H. H. Keifer to the author, August 29, 1952); San Bernardino, 1943; Riverside, 1943; Sacramento, 1944; Imperial, 1944; San Diego, 1944; Yolo, 1944; Ventura, 1947; Santa Barbara, 1947; Santa Clara, 1947; Fresno, 1948; San Joaquin, 1949; Stanislaus, 1949; Merced, 1949; Kern, 1949; Tulare, 1949; Tehama, 1949; Madera, 1949; and Butte, 1950. 
From this list, it is seen that the insect's spread in California has been very rapid. At the present time, it occurs in most of the fruit- and nutproducing areas of the state.

The navel orangeworm is a weak flier and probably does not migrate rapidly by flight. Its spread has undoubtedly been expedited by its transportation in infested materials.

\section{HOST RANGE}

The navel orangeworm is primarily a scavenger and attacks many kinds of fruits and nuts. In the case of fruits, it develops in those that are mature and injured or mummified. In nuts, its feeding is confined to those that are approaching maturity or have been injured in one manner or another. With almonds, the soft-shell varieties are preferred. In the case of walnuts, it freely enters sound nuts once the husks crack, and according to Michelbacher and Davis (1961), it readily attacks developing nuts that have been injured.

The following are among the hosts on which it has been reported.

Citrus. Grapefruit, lemon, and orange.

Deciduous Fruits. Apple, apricot, fig, nectarine, peach, pear, plum, and quince.

Nuts. Almond, pecan, and walnut.

Miscellaneous. Acacia farnesiana pcds, bottle-tree seeds, carob pods, dates (fallen), Genipa americana fruit, honey-locust pods, jujube, loquat, pomegranate, Texas ebony and yucca pods.

The foregoing list indicates that the navel orangeworm is able to complete its development on a wide range of foods. However, no plant should be considered a host unless it enables the insect to complete its life cycle.

\section{EXPERIMENTAL METHODS}

\section{Bait Pans}

For this purpose, five enamel pans were used which measured twelve inches in diameter and six inches deep. A wire hoop was placed under the lip of each pan, to which three vertical supporting wires were attached. The supporting wires were in turn attached to a rope which had been threaded through a pulley attached to a tree branch. By this means, the pans could be raised and lowered at will and placed at any desired height.

The pans were two-thirds filled with fermenting liquid baits, and were serviced every thrce or four days. The contents of each pan were poured into a tea strainer, so that the insects could be retained and the old bait material discarded. The insects were then placed in jars numbered to correspond with the bait pans. The jars were partly filled with water. to facilitate handling of the insects. (For baits used, see "Activity in Almonds," p. 157.)

In the laboratory, the contents of each jar were put into a large dishpan containing water. Here the moths were separated, and all those falling within the size range of the navel orangeworm were retained for further examination and segregation. 


\section{Bait Traps}

Circular pint ice cream cartons were modified to make traps which could be charged with solid attractants. A circular orifice about one and one-half inches in diameter was cut in the bottom of the carton. The orifice was then covered with a fine-mesh wire gauze. The bottom was forced about threefourths the distance into the carton, leaving a chamber for the solid attractant. The wall of the carton below the forced-up bottom was covered with a sticky material known under the trade name of "Dead Line." Three equidistant strings were attached to the lid, so that the traps could be suspended from the same ropes used for the bait pans. (For baits used, see "Activity in Almonds," p. 157.)

\section{Nut Samples}

Seasonal population trends and stages of development were investigated in three varieties of almonds: IXL, Ne Plus Ultra, and Nonpareil. IXL samples were collected at frequent intervals from stick-tights (i.e., nuts remaining on the trees from the preceding year's crop), by gleaning old nuts from beneath the tree, and from the current crop. With the other two varieties, the surveys were the same, except that no study could be made of stick-tights because with these varieties, virtually all nuts are removed during the harvesting process.

With walnuts, both gleanings and stick-tights were utilized in field population studies. When possible, walnuts of several varieties were studied.

In all the field investigations, every effort was made to gather samples of one hundred nuts. The nut samples were taken to the laboratory and carefully examined for eggs and exterior activity. They were then cracked and examined for caterpillars and pupae. The information obtained for each nut was separately recorded. When a nut was found to be infested, the number of individuals and the stage of development were noted.

\section{Maintenance of Stock Cultures in the Laboratory}

Standard one-gallon wide-mouthed mayonnaise jars were about one-third filled with infested nuts taken from the field. The open ends of the jars were covered with fine-mesh cheesecloth which was held in place with a rubber band. A continuous supply of adults was thus made available.

\section{Mating Cages (Indoor and Outdoor)}

Mating cages were basically of two types: those used indoors and those used outdoors. The indoor cages were one- and five-gallon glass cylinders, open at one end. The open ends were covered with fine-mesh cheesecloth which was held in place by rubber bands. A hole was made in the cover so that moths could be introduced, and then was plugged with a cotton wad. A vial of water with a cotton wick was placed in the cage, to supply moisture for the insects.

The outdoor cages were of two sizes. The larger cage measured $36 \times 36 \times 40$ inches. It was covered on five sides with window screen. The sixth side 
was covered with cheesecloth and fitted with a sleeve, to facilitate handling the moths. The smaller cage was of the same general construction, except that it had a solid bottom and only four sides were covered with screen. It measured $10 \times 10 \times 14$ inches.

The cages were set on a platform, the four legs of which were placed in containers of water to prevent ant attacks.

\section{Oviposition Chambers}

Shell vials that measured $2.5 \times 5 \mathrm{~cm}$. were used for oviposition chambers. They were lined with wax paper and stoppered with corks. The corks were bored with a number 4 cork borer to allow aeration. Cheesecloth was placed over the hole to prevent escape of the female moths.

\section{Individual Rearing Cages}

Shell vials, as used for oviposition chambers, were also used for rearing individual larvae. A small "L" tab, made of botany drawing paper and measuring approximately one-half by three-fourths inch, was placed in the vial. The food medium to be tested was placed on the short axis of the " $L$ " tab, while the long axis could be gripped with forceps to facilitate removal. The cages were forcibly aerated daily with a standard-type nasal aspirator, to remove carbon dioxide that might have settled on the bottom. Handling of larvae was done with a camel's-hair brush.

\section{Constant Relative Humidity Chambers}

Standard desiccators containing various salt solutions or weight percentages of concentrated sulfuric acid were used to maintain constant relative humidities. The salt solutions were made by heating water and adding salt until no more would go into solution, and then adding an excess. The weight percentages of sulfuric acid to secure the desired relative humidity were computed, using the method developed by Solomon (1951). Relative humidities $^{5}$ were checked with a Cerdex hygrometer.

\section{Constant Temperature Cabinets}

Cabinets approximately three feet square, fitted with mercury thermostats, were used to maintain constant temperatures, $\pm 1 / 2^{\circ} \mathrm{C}$. Fans were placed in the cabinets to insure uniform temperature conditions. Temperatures were checked daily.

\section{Longevity Vials}

Shell vials, as used for oviposition chambers, were employed to ascertain length of life of adults. Within the longevity vials were placed smaller shell vials measuring $1 \times 2.5 \mathrm{~cm}$, in which water or a sugar-and-water solution was placed. A cotton wick was inserted into the smaller vial, which absorbed the liquid and made it available to the moths.

\footnotetext{
${ }^{5}$ Hereafter, this term will be expressed as "rh." in the text, but will be spelled out in headings.
} 


\section{Mounting Technique}

Living larvae were killed in hot 70 per cent alcohol and held until they could be mounted. With the exception of first-instar larvae, which were too small, excellent mounts were obtained by slitting the specimens ventrally with a delicate, sharp scalpel made from a high-grade steel surgeon's needle. To further facilitate spreading, the integument was slit laterally just behind the head.

For cleaning, the incised larvae were placed in a stender dish containing a solution of 50 per cent lactic acid and 50 per cent alcohol. The stender dishes were then placed in a warm slide oven. The length of exposure ranged from twelve to twenty-four hours, depending upon how rapidly the larvae cleared. After removal from the solution, the integuments were placed in 70 per cent alcohol and all material remaining attached to them was teased away. They were then placed in a mixture which was made up of one-half clove oil and one-half 70 per cent alcohol. The integuments were left in this mixture for approximately twelve hours, after which they were removed and mounted in diaphane on glass slides and placed in the slide oven to dry.

\section{METHODS OF INSTAR DETERMINATION}

There are a number of characters that are useful in determining instars of lepidopterous larvae. The most important of these is the size of the head capsule, which is quite constant for a given stage of a given species. The number and arrangement of the crotchets is also helpful, but is not so constant a character.

\section{Head Capsules}

It was shown by Dyar (1890) that the widths of the head capsules of caterpillars grow in geometrical progression with each instar for any given species.

This rule was applied to navel orangeworm larvae by taking the length and width measurements of a varying number of head capsules from each instar of most rearings.

The data obtained for each instar under a given set of constant conditions were fairly uniform. However, some differences could be detected between given instars when reared under different sets of constant conditions (tables 1 and 2), although in most cases these were not too great.

Head-capsule width measurements were consistently greater than the lengths in all instars except the first, where they were equal. Variations in lengths and widths of head capsules between individuals of the same rearings began in the second instar. These variations continued throughout the succeeding instars. Averages for head-capsule measurements when comparing instars of larvae reared on almonds under different rh. progressively showed a slight increase. Head capsules of larvae reared on walnuts were slightly larger than those reared on almonds.

The information obtained indicates that the instar of any larva can be determined by measuring the head capsule. There was no overlap of instars in the measurements taken under a given set of conditions. All instars pro- 
TABLE 1

HEAD-CAPSULE MEASUREMENTS IN MILLIMETERS OF LARVAE WHEN REARED ON ALMOND AT A CONSTANT TEMPERATURE OF $27.5^{\circ} \mathrm{C}$. AND DIFFERENT CONSTANT RELATIVE HUMIDITIES

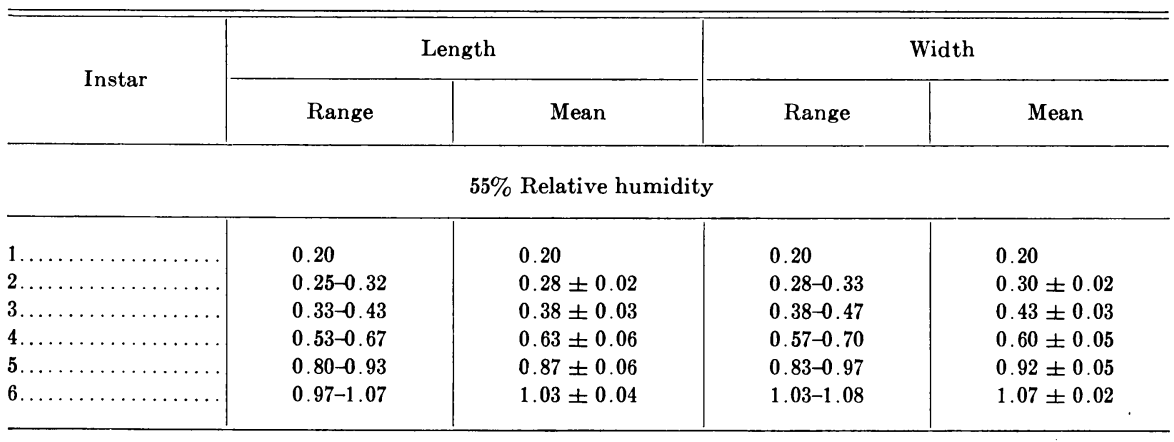

$75 \%$ Relative humidity

\begin{tabular}{|c|c|c|c|c|}
\hline $1 \ldots \ldots \ldots \ldots \ldots \ldots$ & 0.20 & 0.20 & 0.20 & 0.20 \\
\hline $2 \ldots$ & $0.25-0.30$ & $0.28 \pm 0.01$ & $0.27-0.33$ & $0.30 \pm 0.02$ \\
\hline $3 \ldots$ & $0.40-0.50$ & $0.45 \pm 0.02$ & $0.43-0.50$ & $0.47 \pm 0.02$ \\
\hline $4 \ldots$ & $0.61-0.73$ & $0.68 \pm 0.03$ & $0.67-0.77$ & $0.72 \pm 0.03$ \\
\hline $5 \ldots \ldots \ldots$ & $0.93-1.23$ & $1.00 \pm 0.07$ & $0.97-1.20$ & $1.03 \pm 0.05$ \\
\hline
\end{tabular}

$85 \%$ Relative humidity

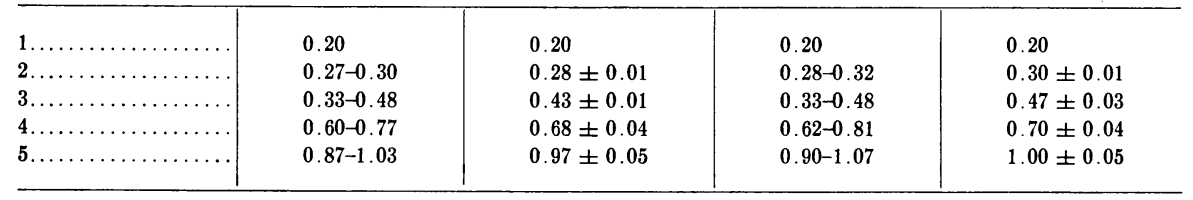

$95 \%$ Relative humidity

\begin{tabular}{|c|c|c|c|c|}
\hline $1 \ldots \ldots \ldots \ldots \ldots \ldots$ & 0.20 & 0.20 & 0.20 & 0.20 \\
\hline $2 \ldots \ldots \ldots \ldots \ldots \ldots$ & $0.27-0.33$ & $0.30 \pm 0.01$ & $0.28-0.33$ & $0.32 \pm 0.01$ \\
\hline $3 \ldots \ldots \ldots \ldots \ldots \ldots$ & $0.40-0.53$ & $0.47 \pm 0.04$ & $0.43-0.57$ & $0.50 \pm 0.09$ \\
\hline $4 \ldots \ldots \ldots \ldots \ldots \ldots$ & $0.67-0.87$ & $0.77 \pm 0.06$ & $0.70-0.90$ & $\theta .81 \pm 0.04$ \\
\hline $5 \ldots \ldots \ldots \ldots \ldots \ldots$ & $0.97-1.10$ & $1.03 \pm 0.05$ & $1.00-1.10$ & $1.07 \pm 0.03$ \\
\hline
\end{tabular}

gressively increased in size and were definitely distinguishable one from the other. In rare instances, however, there were individual cases of overlap between instars under different sets of rearing conditions, but even here these differences were slight and were masked where the measurements were averaged.

\section{Crotchets}

The numbers of crotchets on the prolegs of the several instars were studied. It was found that they were arranged in an irregular biordinal pattern. Often there were one or more large crotchets followed by one to several small ones.

In order to determine the number of crotchets, larval skins of the different instars were mounted on slides and the crotchets on each proleg were 
TABLE 2

HEAD-CAPSULE MEASUREMENTS IN MILLIMETERS OF LARVAE WHEN REARED ON ALMOND AND WALNUT AT A CONSTANT TEMPERATURE OF $27.5^{\circ}$ C. AND A CONSTANT RELATIVE HUMIDITY OF 75 PER CENT

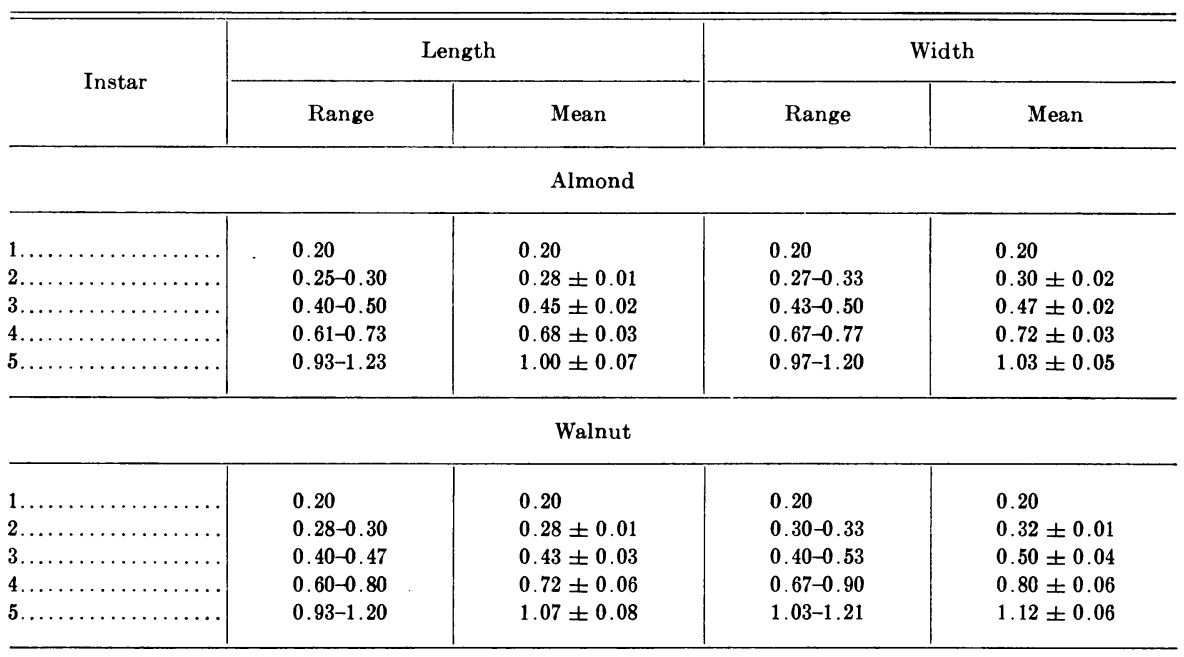

TABLE 3

NUMBER OF CROTCHETS ON A PAIR OF PROLEGS FOR EACH LARVAL INSTAR

\begin{tabular}{|c|c|c|c|c|c|c|}
\hline \multirow{2}{*}{$\begin{array}{l}\text { Number of } \\
\text { crotchets }\end{array}$} & \multicolumn{6}{|c|}{ Instar } \\
\hline & 1 & 2 & 3 & 4 & 5 & 6 \\
\hline First pair & & & & & & \\
\hline Range... & $6-8$ & $9-14$ & $10-17$ & $14-31$ & $20-34$ & $23-35$ \\
\hline Mean...... & $7.27 \pm 0.75$ & $11.56 \pm 1.23$ & $14.90 \pm 1.64$ & $19.11 \pm 3.74$ & $26.47 \pm 4.81$ & $28.16 \pm 5.35$ \\
\hline Second pair & & & & & & \\
\hline Range.... & $6-9$ & $9-14$ & $11-18$ & $14-28$ & $20-31$ & $25-33$ \\
\hline Mean..... & $7.27 \pm 0.83$ & $12.17 \pm 1.16$ & $14.53 \pm 1.84$ & $18.67 \pm 3.39$ & $25.63 \pm 3.54$ & $29.56 \pm 2.07$ \\
\hline Third pair & & & & & & \\
\hline Range.... & $6-9$ & $10-15$ & $12-17$ & $13-28$ & $21-34$ & $22-33$ \\
\hline Mean..... & $7.45 \pm 0.78$ & $12.02 \pm 1.63$ & $14.72 \pm 1.49$ & $18.41 \pm 3.38$ & $26.18 \pm 3.89$ & $28.97 \pm 2.55$ \\
\hline Fourth pair & & & & & & \\
\hline Range.... & $6-9$ & $10-15$ & $10-16$ & $14-26$ & $17-33$ & $21-33$ \\
\hline Mean..... & $7.47 \pm 0.88$ & $12.27 \pm 1.65$ & $14.10 \pm 1.64$ & $18.70 \pm 3.22$ & $25.32 \pm 4.71$ & $27.76 \pm 2.89$ \\
\hline Anal & & & & & & \\
\hline Range..... & $5-7$ & $6-9$ & $10-11$ & $8-19$ & $13-22$ & $16-25$ \\
\hline Mean... .. & $6.17 \pm 0.58$ & $7.03 \pm 0.88$ & $10.54 \pm 0.54$ & $12.85 \pm 2.78$ & $16.33 \pm 2.55$ & $21.20 \pm 2.48$ \\
\hline
\end{tabular}

counted. This was accomplished by using an inverted microseope which projected the image onto a white background.

Table 3 shows the range and mean number of crotchets on a proleg of each pair found in different instars. Also given are the range and mean number of crotchets on an anal proleg of each pair.

The number of crotchets increases as the larvae progress from one instar to the next. Within an instar, the number of crotchets shows considerable 


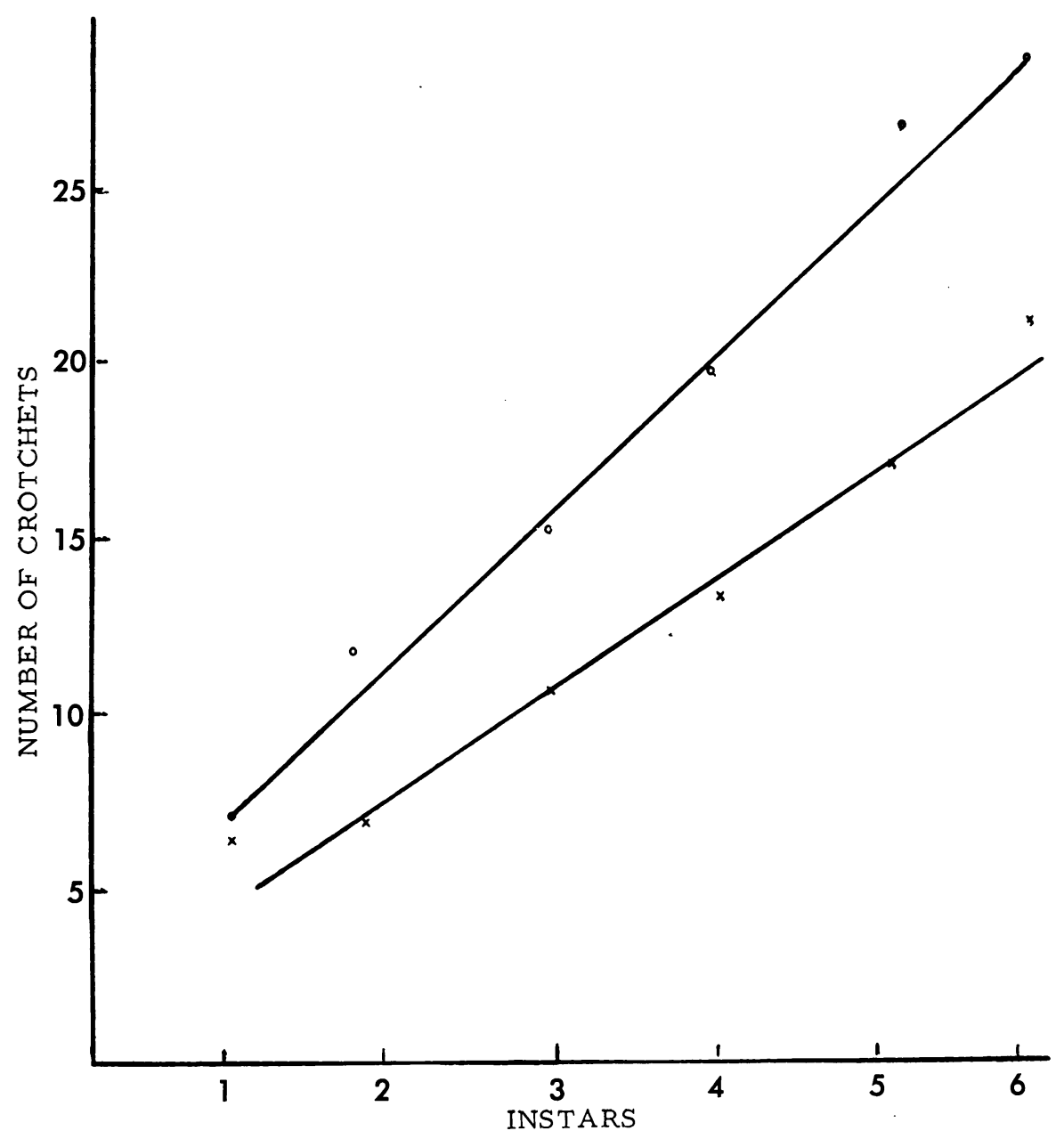

Fig. 11. Average number of crotchets on the prolegs of each larval instar of the navel orangeworm. $O$ : Abdominal prolegs. $X$ : Anal prolegs.

variation. Despite the variation encountered, the average number of crotchets for the abdominal prolegs and anal prolegs of the several instars shows a progressive and rather constant increase. This is clearly indicated in figure 11, where the average number of crotchets for each instar is plotted. It is interesting to note that the rate of increase in the case of the anal prolegs is less than for the abdominal prolegs. This is clearly illustrated by the slope of the lines. Observations were also made which showed that the number of crotchets on the prolegs of a pair is not constant. However, in no case was a wide variation encountered.

The results show that head-capsule measurements and the number of crotchets present can be utilized in accurately determining larval instars. 


\section{MATING}

Individuals used in mating studies were reared from infested almonds and walnuts collected in the field. To insure an ample supply of adults, large stock cultures were maintained at all times. The moths were extremely reluctant to mate, and in order to determine the factors that had a bearing upon this response, extensive experiments were conducted in the laboratory and outdoors. Observations were made at all hours of the day and night.

\section{Laboratory Investigations}

These studies were conducted under room conditions. The temperatures averaged $25^{\circ} \mathrm{C}$. and the rh. averaged close to 50 per cent. As stated before, one- and five-gallon mating cages were used. The one-gallon cages offered a very unfavorable environment, and little mating activity was observed. From these cages, not enough eggs were ever obtained to make it possible to carry on rearing experiments. The conditions offered in the five-gallon cages were more favorable, and while the moths would not mate freely, there was sufficient activity to insure a continuous supply of fertile eggs for investigational studies.

In both types of mating cages, the moths would take a position on the side of the cage from which the light entered and remain inactive for an indefinite period. At night, if the lights were turned on, the adults became active for a short period but never showed any proclivity toward courtship or mating.

The few occurrences of mating and copulation that were observed seemed confined to the early-morning hours. From these observations, it was concluded that a combination of factors present only during this period tended to induce mating. Because mating occurred more frequently in the fivegallon than in the one-gallon cages, it was believed that a still larger cage might favor an increase in its incidence.

\section{Outdoor Investigations}

Studies were conducted in cages located outdoors from July 13 until September 24, 1953. As already stated, two sizes of cages were used. One was large, measuring $36 \times 36 \times 40$ inches; the other was small, measuring $10 \times 10 \times 14$ inches. The cages were of similar construction, having the sleeve side covered with cheesecloth. The remaining surfaces were covered with window screen; the small cage differed in having a solid bottom. Moths were placed in the cages at a ratio of two for the large to one for the small cage. Every effort was made to distribute the sexes equally.

Because the laboratory investigations showed that factors in the early morning favored mating, activity in the outdoor cages was observed carefully during this period from July 24 through July 31 . This vigil started before sunrise, at almost 4 o'clock, and usually terminated about 7 o'clock. The temperature and humidity were observed upon arrival and at departure. The temperature on arrival ranged from 11 to $15^{\circ} \mathrm{C}$., while at departure the range was 17 to $26^{\circ} \mathrm{C}$. The rh. at arrival ranged from 82 to 85 per cent, while at departure the range was 81 to 85 per cent. 
During the period under observation, mating occurred on a number of occasions. This happened over a period that extended from some time before 4 o'clock until about 7 o'clock. Apparently, weather conditions exerted little influence, for mating occurred equally well in the presence or absence of a breeze or fog.

During these early-morning observations, many courtships were witnessed. Although numerous acts of copulation were observed, in only one instance was courtship, followed by copulation, actually noted.

Courtship took place before it was light enough to see, which made it necessary to use a flashlight to observe this activity. Every effort was made to avoid flashing the light directly upon individuals. In courtship, the female raises her abdomen to a vertical position between the wings. After a short period of time, the male is stimulated in some manner (possibly by scent) and begins to flutter his wings rapidly and move toward the female. The path followed is not always in a direct line, and at times it is very erratic. The female remains motionless, and the male always approaches her from the rear. As the male nears the female, he curves his abdomen around in an attempt to make contact with her, all the time fluttering his wings very rapidly. Except for the one case where mating was completed, the female at this point would lower her abdomen and move not rapidly or far, but yet out of reach of the male. The male, in some cases, would proceed to follow the female, or would quiet down or pursue another female. The female might, after a few minutes, raise her abdomen again or continue to remain quiet. Frequently, more than one male would seek out a single female. In the one case where the male succeeded in making contact, the copulating pair quieted down, the wings of the female covering the male. It is interesting to note that the majority of mating pairs were found on the side of the cage covered with white cheesecloth.

The length of the copulation period ranged from two to four hours, but on one occasion it was observed to last from at least 8 A.M. until 5 P.M., or a total of not less than nine hours.

During the period that the investigation was conducted outdoors, fortyone mating pairs were taken from the large cage and twenty-eight pairs from the small one. Although more pairs were taken from the large cage, it does not necessarily mean that conditions in the latter were more favorable for mating. There were twice as many moths in the large as in the small eage, and for this reason, more mating pairs might be expected. However, one other factor must be taken into consideration: The volume of the large cage was thirty-seven times that of the small one, and therefore the chances of individuals meeting in the large cage conceivably could have been fewer than those encountered in the small one.

Premating Period. An experiment was performed in order to determine the premating period after emergence, or at least to determine how long afterward the moths might still have a proclivity to mate.

Freshly emerged adults were counted and sexed each day for four days. The moths emerging the first day were left unstained, those emerging the second day were stained red (using gentian violet), those emerging the third day were stained green (using malachite green), and those emerging 
the fourth day were stained black (using India ink). They were introduced into the outdoor mating cages the same day they emerged. Because of the maximum difference in the age of the individuals, it was possible for a moth to mate with another moth of the same age or one, two, or three days older.

As they mated, the pairs were removed and their color markings were noted and recorded. In this way, it could be determined how many days the moth had lived before mating.

TABLE 4

NUMBER OF DAYS FOLLOWING EMERGENCE THAT MALES AND FEMALES WILL MATE AND PERIOD OF HIGHEST FREQUENCY OF MATING

\begin{tabular}{|c|c|c|c|c|c|c|c|c|c|}
\hline \multicolumn{2}{|c|}{ Total individuals } & \multicolumn{8}{|c|}{ Number of individuals mating on indicated days following emergence } \\
\hline \multirow{2}{*}{ Males } & \multirow{2}{*}{ Females } & \multicolumn{2}{|c|}{ First day } & \multicolumn{2}{|c|}{ Second day } & \multicolumn{2}{|c|}{ Third day } & \multicolumn{2}{|c|}{ Fourth day } \\
\hline & & Males & Females & Males & Females & Males & Females & Males & Females \\
\hline 27 & 27 & 13 & 10 & 11 & 12 & 2 & 2 & 1 & 3 \\
\hline
\end{tabular}

During the course of this experiment, the large cage received 151 moths while the small cage received 70 moths. Of this total, 54 individuals mated over an eight-day period, but no mating occurred with individuals more than four days old. Sixteen copulatory pairs were taken from the small cage, while eleven pairs were obtained from the large one. The results in regard to the age of individuals at time of mating are given in table 4 .

It is evident that most of the individuals mated within the first two days, and none after four days. Beyond this time, there was no apparent desire to copulate, although the moths actually lived longer than four days. The first and second days following emergence were obviously the periods when greatest copulation took place. In the laboratory, it was further substantiated that most mating occurred during the first twenty-four hours.

\section{OVIPOSITION}

The moths oviposited readily under laboratory conditions. Newly emerged females oviposited regularly, even though they had not mated. They deposited eggs on the sides of the mating cages, and in the oviposition chambers they laid freely on the wax-paper linings. The eggs were usually laid in groups ranging from two to thirty, and in many eases they slightly

TABLE 5

LONGEVITY IN DAYS OF FEMALES FOLLOWING MATING AND NUMBER OF EGGS DEPOSITED*

\begin{tabular}{|c|c|c|c|}
\hline \multirow{2}{*}{$\begin{array}{l}\text { Length of life } \\
\text { following mating }\end{array}$} & \multirow{2}{*}{$\begin{array}{l}\text { Length of ovi- } \\
\text { position period }\end{array}$} & \multicolumn{2}{|c|}{ Number of eggs laid per female } \\
\hline & & Range & Mean \\
\hline 2-12 days & 1-9 days & $3-244$ & 84.6 \\
\hline
\end{tabular}

* Based on 130 mated female moths. 
overlapped one another. In the field, this behavior was not observed, and a maximum of three eggs was the largest grouping encountered. The confinement of the females and the reduced oviposition area probably account for the situation encountered in the laboratory. Records from 130 fecund females indicated they would deposit eggs from 1 to 9 days. The number of eggs laid per female ranged from 3 to 244 , with a mean of 84.6 eggs (table 5).

The number of eggs laid in any one day ranged from none to a maximum of 179 . Normally, highest deposition occurred during the first day or two and then gradually diminished, although in certain cases deposition built up to a peak on the second and third days and then gradually tapered off. Oviposition did not take place every day, for in several instances a period of a day or two elapsed between egg laying. Usually, when the rate of oviposition was extremely high the first day or two, the total oviposition period was short. However, if the daily egg deposition was low, the duration of the egg-laying period was extended.

Egg deposition was observed in the case of eight unfertilized females. The number of eggs deposited ranged from 19 to 102, and the period of deposition ranged from 2 to 5 days.

Although unfertilized females usually laid fewer eggs than did fertilized individuals, the data obtained in this study indicated that the females contained a relatively fixed number of mature eggs at the time they emerged from pupation. To substantiate this, newly emerged females were dissected and were found to contain many mature eggs. The failure to obtain eggs in the case of some of the mated females might be accounted for by the fact that the individuals had deposited their quota of eggs before mating took place.

Under field conditions on almond, navel orangeworm adults were observed to oviposit anywhere on the mature nut. Freshly laid and hatched eggs were found on the hulls, shells, and on the meats if they were exposed. Some eggs were placed in areas of concealment between the hull and shell. Eggs in rather large numbers were also found deposited on the twigs several inches from the nut, and on mummies.

\section{LABORATORY REARINGS}

It is known that certain environmental conditions are more conducive to insect growth and development than are others. The navel orangeworm was reared on different foods at several constant temperatures and $\mathrm{rh}$. in order to determine the influence of these factors on its development.

\section{Incubation Period}

The incubation period of an egg is primarily determined by temperature and perhaps secondarily by rh. Under adverse conditions, the incubation period is modified, and finally a point is reached where the eggs are killed.

Influence of Temperature and Relative Humidity. The effects of temperature and $\mathrm{rh}$. on the incubation period of navel orangeworm eggs were determined by placing freshly laid eggs in constant environments of known temperature and humidity. 
The responses to constant temperatures of 2.5, 10, 15, 25, 27.5, 30, and $35^{\circ} \mathrm{C}$., and constant $\mathrm{rh}$. of $55,75,85$, and 95 per cent were investigated.

At temperatures below $15^{\circ} \mathrm{C}$. and 75 per cent rh., all eggs failed to hatch. The data for temperatures of $15^{\circ} \mathrm{C}$. and higher are given in table 6 , and are reviewed below.

TABLE 6

DURATION IN DAYS OF VARIOUS STAGES OF THE NAVEL ORANGEWORM WHEN REARED ON ALMOND AT DIFFERENT CONSTANT TEMPERATURES AND RELATIVE HUMIDITIES

\begin{tabular}{|c|c|c|c|c|c|c|c|c|}
\hline \multirow{2}{*}{$\begin{array}{l}\text { Relative humidity } \\
\text { (per cent) }\end{array}$} & \multicolumn{2}{|c|}{ Egg } & \multicolumn{2}{|c|}{ Larva } & \multicolumn{2}{|c|}{ Pupa } & \multicolumn{2}{|c|}{ Total } \\
\hline & Range & Mean & Range & Mean & Range & Mean & Range & Mean \\
\hline
\end{tabular}

$15^{\circ} \mathrm{C}$.

\begin{tabular}{l|l|l|l|l|l|l|l|l}
\hline $75 \ldots \ldots \ldots \ldots \ldots \ldots$ & $21-23$ & 22.4 & $108-194$ & 170.7 & $\ldots \ldots$ & $\ldots$ & $\ldots \ldots$ & $\ldots$ \\
\hline
\end{tabular}

$25^{\circ} \mathrm{C}$.

\begin{tabular}{l|l|l|l|l|l|l|l|l}
\hline $75 \ldots \ldots \ldots \ldots \ldots \ldots$ & $5-6$ & 5.6 & $40-70$ & 54.9 & $9-14$ & 11.0 & $54-90$ & 71.6 \\
\hline
\end{tabular}

$27.5^{\circ} \mathrm{C}$.

\begin{tabular}{l|r|r|r|r|r|r|r|r}
\hline $55 \ldots \ldots \ldots \ldots \ldots \ldots \ldots$ & 5 & 5.0 & $41-71$ & 55.4 & $6-11$ & 8.2 & $52-88$ & 68.7 \\
$75 \ldots \ldots \ldots \ldots \ldots \ldots \ldots$ & 5 & 5.0 & $34-58$ & 42.8 & $6-10$ & 7.4 & $45-74$ & 55.3 \\
$85 \ldots \ldots \ldots \ldots \ldots \ldots \ldots \ldots$ & 5 & 5.0 & $35-56$ & 40.6 & $9-12$ & 10.0 & $49-74$ & 55.7 \\
$95 \ldots \ldots \ldots \ldots \ldots \ldots \ldots$ & 5 & 5.0 & $16-27$ & 21.8 & $5-10$ & 6.8 & $26-43$ & 33.7 \\
\hline
\end{tabular}

$30^{\circ} \mathrm{C}$.

\begin{tabular}{l|l|l|l|l|l|l|l|l|}
\hline $75 \ldots \ldots \ldots \ldots \ldots \ldots$ & $5-6$ & 5.3 & $29-71$ & 42.9 & $7-10$ & 7.7 & $41-87$ & 58.5 \\
\hline
\end{tabular}

$35^{\circ} \mathrm{C}$ *

\begin{tabular}{l|l|l|l|l|l|l|l|l}
\hline $75 \ldots \ldots \ldots \ldots \ldots$ & $5-6$ & 5.1 & $\ldots \ldots$ & $\ldots$ & $\ldots \ldots$ & $\ldots$ & $\ldots$ & $\ldots$ \\
\hline
\end{tabular}

* Data were recorded for eggs only.

Of thirty-one eggs placed at $15^{\circ} \mathrm{C}$. and 75 per cent $\mathrm{rh}$., three hatched in twenty-one days, eight in twenty-two days, and thirteen in twenty-three days. Seven failed to hatch, but nonfertilization was suspected because they had collapsed three days following their deposition without showing any signs of development.

Sixteen eggs placed at $25^{\circ} \mathrm{C}$. and 75 per cent rh. colored up one day later. Seven hatched in five days and nine in six days.

All eggs held at $27.5^{\circ} \mathrm{C}$. and $\mathrm{rh}$. of $55,75,85$, and 95 per cent hatched in five days.

Of twenty-one eggs held at $30^{\circ} \mathrm{C}$. and 75 per cent rh., fourteen hatched in five days and the remainder in six days.

Out of forty eggs held at $35^{\circ} \mathrm{C}$. and 75 per cent relative humidity, twentyseven hatched in five days and thirteen hatched in six days.

From the above data, it can be seen that eggs failed to hatch at tempera- 
tures below $15^{\circ} \mathrm{C}$. As seen in table 6 , the incubation period was considerably extended at $15^{\circ} \mathrm{C}$. and 75 per cent rh., while at the remaining temperatures the incubation period was rather short. Little difference could be detected between $30^{\circ} \mathrm{C}$. and 75 per cent rh. and $35^{\circ} \mathrm{C}$. and 75 per cent $\mathrm{rh}$. The optimum temperature appeared to be about $27.5^{\circ} \mathrm{C}$. The quickest and most uniform hatch occurred at this temperature. The range of rh. used in these experiments apparently exerted little or no effect upon the incubation period.

TABLE 7

NUMBER OF LARVAL INSTARS WHEN REARED

ON ALMOND AT DIFFERENT CONSTANT

TEMPERATURES AND RELATIVE HUMIDITIES

\begin{tabular}{|c|c|c|c|c|}
\hline \multirow{2}{*}{$\begin{array}{c}\text { Relative } \\
\text { humidity } \\
\text { (per cent) }\end{array}$} & \multirow{2}{*}{$\begin{array}{l}\text { Number of } \\
\text { individuals }\end{array}$} & \multicolumn{3}{|c|}{ Number of instars } \\
\hline & & Five & Six & Seven \\
\hline \multicolumn{5}{|c|}{$25^{\circ} \mathrm{C}$. } \\
\hline $75 .$. & 16 & 1 & 14 & 1 \\
\hline \multicolumn{5}{|c|}{$27.5^{\circ} \mathrm{C}$. } \\
\hline 55 . & 14 & 0 & 9 & 5 \\
\hline 75. & 17 & 3 & 14 & 0 \\
\hline $85 \ldots \ldots \ldots$ & 5 & 1 & 4 & 0 \\
\hline $95 \ldots \ldots \ldots \ldots$ & 10 & 8 & 2 & 0 \\
\hline \multicolumn{5}{|c|}{$30^{\circ} \mathrm{C}$. } \\
\hline 75. & 15 & 0 & 3 & 12 \\
\hline
\end{tabular}

\section{Larval Instars}

With most insects, the smallest number of instars usually occurs when they are reared under optimum conditions (Michelbacher, 1953). Therefore, the number of instars can be utilized as one means of determining suitability of rearing conditions. With this in mind, several rearings of the navel orangeworm were conducted in which the roles of temperature and $\mathrm{rh}$. were investigated. In another series of experiments, the influence of the host was considered.

Roles of Temperature and Relative Humidity. In these studies, almond meats were used as food, and the navel orangeworm was reared at several different constant temperatures and constant $\mathrm{rh}$.

The temperatures and the rh. investigated, along with the results obtained, are given in table 7 . Under none of the conditions studied was the number of instars constant. They varied from five to seven. Although based upon only ten individuals, the fewest instars occurred at $27.5^{\circ} \mathrm{C}$. and 95 per cent rh. Here eight larvae completed development in five instars. The next best was at $27.5^{\circ} \mathrm{C}$. and 75 per cent rh., which was closely followed by $25^{\circ} \mathrm{C}$. and 75 per cent $\mathrm{rh}$. In the latter case, one out of sixteen indi- 
viduals completed development in seven instars. At $30^{\circ}$ C. and 75 per cent rh., none of fifteen individuals completed larval development in five instars, and twelve needed seven instars. It is obvious from this that $30^{\circ} \mathrm{C}$. is beyond the optimum range in temperature. Where rearings were conducted at $27.5^{\circ} \mathrm{C}$. and 55 per cent rh., nine of fourteen individuals had six instars and five had seven instars, which clearly shows that a rh. of 55 per cent is below the optimum.

From these results, based upon the number of instars, it can be concluded that the optimum temperature for development ranges between 25 and $27.5^{\circ} \mathrm{C}$., and that the most favorable rh. is between 75 and 95 per cent.

TABLE 8

NUMBER OF LARVAL INSTARS WHEN REARED ON ALMOND AND WALNUT AT A CONSTANT TEMPERATURE OF $27.5^{\circ} \mathrm{C}$. AND A CONSTANT RELATIVE HUMIDITY OF 75 PER CENT

\begin{tabular}{|c|c|c|c|}
\hline \multirow{2}{*}{ Food } & \multirow{2}{*}{$\begin{array}{l}\text { Number } \\
\text { of indi- } \\
\text { viduals }\end{array}$} & \multicolumn{2}{|c|}{ Number of instars } \\
\hline & & Five & Six \\
\hline $\begin{array}{l}\text { Almond ............ } \\
\text { Walnut........... }\end{array}$ & $\begin{array}{l}17 \\
15\end{array}$ & $\begin{array}{l}3 \\
5\end{array}$ & $\begin{array}{l}14 \\
10\end{array}$ \\
\hline
\end{tabular}

Role of Host. Although the navel orangeworm feeds upon a number of hosts, in these investigations it was successfully reared in numbers only on almond and walnut. At a constant temperature of $27.5^{\circ} \mathrm{C}$. and $\mathrm{rh}$. of 75 per cent, individuals completed their larval development in five and six instars. The data appear in table 8 , and show that there is little to choose between the two hosts. However; walnut appears to be slightly favored because relatively more individuals completed development in five instars.

\section{Duration of Development}

The rate of development can be used as a guide in determining optimum conditions for a given species. However, it is recognized that the fastest rate of development does not necessarily mean that it is the most favorable one. Other factors must be taken into consideration, for the general wellbeing of the insect must be considered. Important items that influence speed of development include temperature, rh., and suitability of food.

Influence of Temperature and Relative Humidity. The periods spent in egg, larval, and pupal stages were recorded in a number of experiments where the navel orangeworm was reared at various constant temperatures and constant $\mathrm{rh}$. The temperatures and $\mathrm{rh}$. investigated, along with the information obtained, are given in table 6 . At $15^{\circ} \mathrm{C}$. and 75 per cent rh., the insect was unable to complete its development, although a few were able to complete larval growth at a mean of 170.7 days. It is evident that these conditions are close to the threshold of development where the entire rearing of all stages can be completed.

Field investigations show that larvae well along in growth can complete their development in nature when exposed to temperatures that approach 


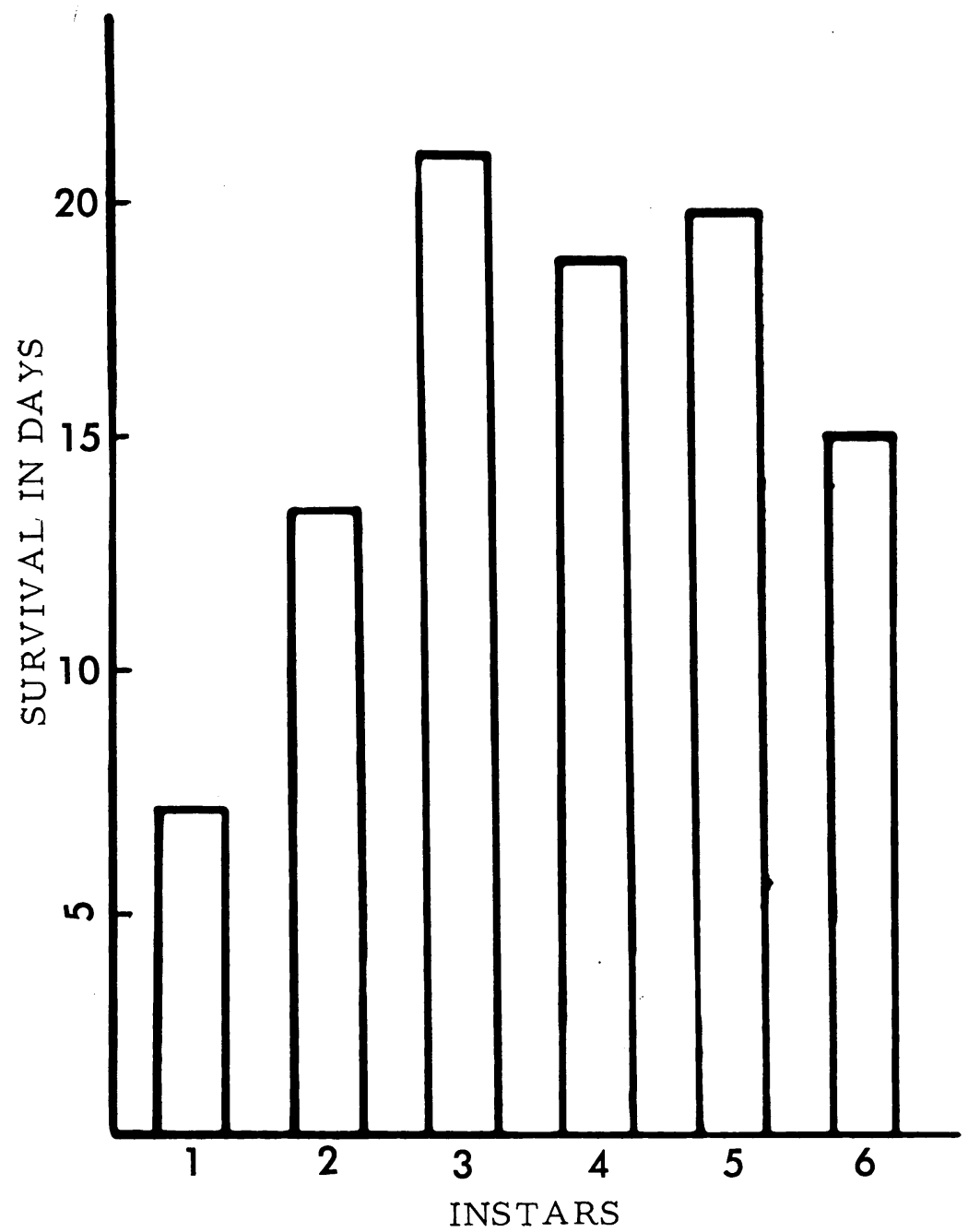

Fig. 12. Resistance to cold of each larval instar of the navel orangeworm at $2.5^{\circ} \mathrm{C}$. and 75 per cent relative humidity.

$15^{\circ}$ C. for somewhat lengthy periods. In the section, "Activity in Almonds," it is shown that partially grown larvae are able to continue their growth throughout the winter. As a matter of fact, this is a means of passing the winter in the field.

Larvae can withstand considerable cold, as was shown in an experiment where different larval instars were exposed to a temperature of $2.5^{\circ} \mathrm{C}$. and rh. of 75 per cent until they died. The average survival in days for the different instars, when exposed to the above conditions, is graphically shown in figure 12. First-instar larvae were the least resistant, while the third to fifth instars, inclusive, were the most tolerant. Strangely enough, resistance of sixth-instar larvae declined appreciably below that of the 
three preceding ones. However, in all cases individuals lived for a period of a week or more, which indicates that in the field the insect can survive periods of relatively cold weather for a considerable time.

Development at $25^{\circ} \mathrm{C}$. and 75 per cent rh., as shown in table 6 , was lengthened over that at $27.5^{\circ} \mathrm{C}$. and 75 per cent rh. Development under the latter conditions was slightly more rapid than at $30^{\circ} \mathrm{C}$. and 75 per cent rh. The increase occurring at $30^{\circ} \mathrm{C}$. and 75 per cent rh. definitely indicates that $30^{\circ} \mathrm{C}$. is beyond the optimum temperature range.

\section{TABLE 9}

DURATION OF DEVELOPMENT IN DAYS OF THE NAVEL ORANGEWORM WHEN REARED ON DIFFERENT HOSTS AT A CONSTANT TEMPERATURE OF $27.5^{\circ}$ C. AND A CONSTANT RELATIVE HUMIDITY OF 75 PER CENT

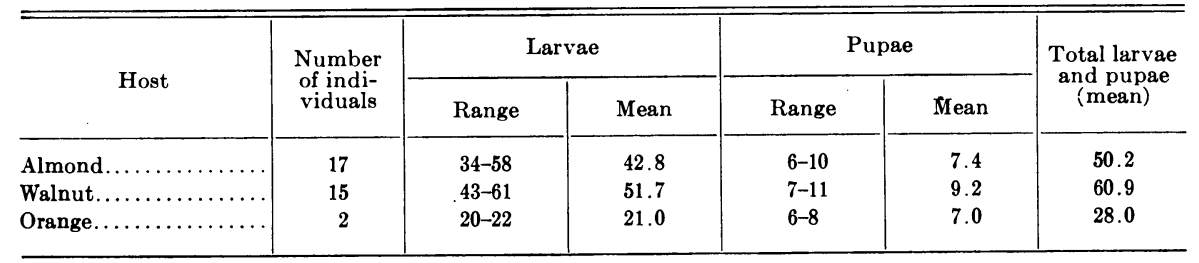

Turning to the other humidities at $27.5^{\circ} \mathrm{C}$., it is noted that the longest period of development occurred at 55 per cent and the shortest at 95 per cent. This shows that 55 per cent $r$. is well below the optimum and that 95 per cent approaches the optimum. It should also be pointed out that in these investigations, the lowest mortality occurred at $27.5^{\circ} \mathrm{C}$. and 75 per cent $\mathrm{rh}$. Considered with other available information, the rearing records presented in table 6 would seem to indicate that the optimum temperature approaches $27.5^{\circ} \mathrm{C}$. and the most favorable rh. is at least 75 per cent or higher.

Influence of Host. Although the navel orangeworm breeds on many hosts, detailed investigations in the present study were limited to almond, walnut, and ripe orange. Orange was included in order to determine whether it was possible for the insect to complete its development on ripe fruit. The rearings were conducted at a constant temperature of $27.5^{\circ} \mathrm{C}$. and $\mathrm{rh}$. of 75 per cent. The information obtained is given in table 9 .

Although development was outstandingly rapid on orange, not too much reliance can be placed on the data obtained because only two individuals completed their life cycle. Rearing was made difficult because of the perishable nature of orange under the conditions used in the experiment. It was necessary to change the food each day, which called for excessive handling of the larvae. This no doubt contributed to the high degree of mortality encountered. In spite of the rapid development, orange, as used in this investigation, must be considered an "unnatural" food. There is ample evidence to show that in nature, sound, ripe oranges are adequately protected by the rind.

Development on almond was more rapid than on walnut. This, taken by itself, would indicate that the former was the more favorable host. On walnut, however, more individuals matured in fewer instars. 


\section{Length of Adult Life}

Adults were maintained under the same conditions at which the immature stages of the navel orangeworm developed. The rearings were at constant temperatures of $25,27.5$ and $30^{\circ} \mathrm{C}$. The rh. figures were the same as given for these temperatures in table 6 . There was a tendency for the adults to live longest at $25^{\circ} \mathrm{C}$. and 75 per cent rh. and to perish sooner at the highest

TABLE 10

WEIGHTS IN GRAMS OF PUPAE REARED ON ALMOND AT DIFFERENT CONSTANT TEMPERATURES AND DIFFERENT CONSTANT RELATIVE HUMIDITIES

\begin{tabular}{|c|c|c|c|c|c|}
\hline \multirow{2}{*}{$\begin{array}{l}\text { Relative } \\
\text { humidity } \\
\text { (per cent) }\end{array}$} & \multicolumn{2}{|c|}{ Females } & \multicolumn{2}{|c|}{ Males } & \multirow{2}{*}{$\begin{array}{l}\text { Femakes } \\
\text { and } \\
\text { males } \\
\text { (mean) }\end{array}$} \\
\hline & Range & Mean & Range & Mean & \\
\hline \multicolumn{6}{|c|}{$25^{\circ} \mathrm{C}$. } \\
\hline 75. & $0.0270-0.0536$ & $0.0372 \pm 0.010$ & $0.0213-0.0312$ & $0.0258 \pm 0.010$ & 0.0313 \\
\hline \multicolumn{6}{|c|}{$27.5^{\circ} \mathrm{C}$} \\
\hline 55. & $0.0144-0.0236$ & $0.0211 \pm 0.005$ & $0.0139-0.0280$ & $0.0185 \pm 0.003$ & 0.0198 \\
\hline 75. & $0.0245-0.0438$ & $0.0337 \pm 0.005$ & $0.0155-0.0342$ & $0.0250 \pm 0.005$ & 0.0295 \\
\hline 85. & $0.0231-0.0414$ & $0.0323 \pm 0.020$ & $0.0229-0.0301$ & $0.0264 \pm 0.004$ & 0.0293 \\
\hline $95 \ldots \ldots \ldots \ldots$ & 0.0391 & 0.0391 & $0.0236-0.0319$ & $0.0282 \pm 0.030$ & 0.0337 \\
\hline
\end{tabular}

$30^{\circ} \mathrm{C}$.

\begin{tabular}{l|c|c|c|c|c}
\hline $75 \ldots \ldots \ldots \ldots \ldots \ldots$ & $0.0241-0.0365$ & $0.0308 \pm 0.52$ & $0.0116-0.0290$ & $0.0204 \pm 0.52$ & 0.0256 \\
\hline
\end{tabular}

temperature. Those held at $27.5^{\circ} \mathrm{C}$. and 55 per cent rh. were also rather short-lived, indicating that dryness is unfavorable to the adults. Even under what might be considered favorable conditions, the length of adult life was only eleven to twelve days.

\section{Pupal Weights and Lengths}

The size of individuals is a useful aid in determining favorable conditions for development. Such measurements are sometimes difficult to make. However, in the case of the navel orangeworm, weighing and measurement of the pupae were undertaken. These were investigated in relation to temperature, rh., and the influence of host.

Influence of Temperature and Relative Humidity. In order to aid in the evaluation of the influence of constant temperature and $\mathrm{rh}$. upon the insect's development, pupal weights and measurements were taken within twenty-four hours after pupation occurred.

The information obtained on pupal weights is given in table 10. At all temperatures and humidities, the females tended to weigh more than the males. When rearings were conducted at $25,27.5$, and $30^{\circ} \mathrm{C}$. at a constant rh. of 75 per cent, the weight of the individuals decreased with an increase 
in temperature. This decrease was much more marked between 27.5 and $30^{\circ} \mathrm{C}$. than it was between 25 and $27.5^{\circ} \mathrm{C}$.

At $27.5^{\circ}$ C., rearings were conducted at $55,75,85$, and 95 per cent $\mathrm{rh}$. Here, as seen in table 10, the weights increased with an increase in rh. There was a very appreciable increase between 55 and 75 per cent rh., little difference between 75 and 85 per cent, and a noted increase from 85 to 95 per cent.

TABLE 11

LENGTHS IN MILLIMETERS OF PUPAE REARED ON ALMOND AT DIFFERENT CONSTANT TEMPERATURES AND DIFFERENT CONSTANT RELATIVE HUMIDITIES

\begin{tabular}{c|c|c|c|c|c|}
\hline \multirow{2}{*}{$\begin{array}{c}\text { Relative humidity } \\
\text { (per cent) }\end{array}$} & \multicolumn{2}{|c|}{ Females } & \multicolumn{2}{c}{ Males } & $\begin{array}{c}\text { Females } \\
\text { and } \\
\text { males } \\
\text { (mean) }\end{array}$ \\
\cline { 2 - 5 } & Range & Mean & Range & Mean & . \\
\hline
\end{tabular}

$25^{\circ} \mathrm{C}$.

\begin{tabular}{l|c|c|c|c|c}
\hline $75 \ldots \ldots \ldots \ldots \ldots \ldots \ldots$ & $8.75-11.00$ & $9.78 \pm 0.66$ & $8.00-9.50$ & $8.64 \pm 0.64$ & 9.22 \\
\hline
\end{tabular}

$27.5^{\circ} \mathrm{C}$.

\begin{tabular}{l|c|c|c|c|c}
\hline $55 \ldots \ldots \ldots \ldots \ldots \ldots \ldots$ & $7.25-9.00$ & $8.17 \pm 0.61$ & $7.25-8.50$ & $7.92 \pm 0.41$ & 8.05 \\
$75 \ldots \ldots \ldots \ldots \ldots \ldots \ldots \ldots$ & $8.25-10.75$ & $9.69 \pm 0.66$ & $7.50-9.50$ & $8.72 \pm 0.65$ & 9.21 \\
$85 \ldots \ldots \ldots \ldots \ldots \ldots \ldots \ldots$ & $8.75-10.50$ & $9.63 \pm 1.22$ & $8.75-9.50$ & $9.08 \pm 0.38$ & 9.35 \\
$95 \ldots \ldots \ldots \ldots \ldots \ldots \ldots$ & 10.00 & 10.00 & $8.50-9.50$ & $9.11 \pm 0.35$ & 9.55 \\
\hline
\end{tabular}

$30^{\circ} \mathrm{C}$.

\begin{tabular}{l|c|c|c|c|c}
\hline $75 \ldots \ldots \ldots \ldots \ldots \ldots \ldots$ & $9.50-10.00$ & $9.69 \pm 0.03$ & $7.00-9.25$ & $8.31 \pm 0.72$ & 8.99 \\
\hline
\end{tabular}

The data on pupal lengths are given in table 11. As would be expected, the information substantiates the data given for pupal weights. Female pupae tend to be longer than those of the males. Where rearings were conducted at a constant rh. of 75 per cent, the length decreased as the temperature increased from 25 to $30^{\circ}$ C. However, there was no significant difference between 25 and $27.5^{\circ} \mathrm{C}$. At $27.5^{\circ} \mathrm{C}$., the length of pupae increased as the rh. increased from 55 to 95 per cent. The most pronounced gain occurred between 55 and 75 per cent.

Influence of Host. Weights and measurements were recorded twentyfour hours after pupation took place. The information obtained is given in table 12. Those reared on ripe orange were the largest and heaviest, but, as already noted, as used in this study, orange must be considered an "unnatural" host. Furthermore, only two individuals survived, owing to the many difficulties encountered in the rearing method that was followed. However, if the larvae could gain entry to the pulp, orange would probably be a highly satisfactory host if the data were viewed in the light of the information given in table 9, which shows that development was much more rapid on orange than on either almond or walnut. The differences in length and weight on almond and walnut were too slight to be of any real significance. 
TABLE 12

WEIGHT OF PUPAE IN GRAMS AND LENGTH OF PUPAE IN MILLIMETERS WHEN REARED ON DIFFERENT HOSTS AT A CONSTANT TEMPERATURE OF $27.5^{\circ}$ C. AND A CONSTANT RELATIVE HUMIDITY OF 75 PER CENT

\begin{tabular}{|c|c|c|c|c|c|c|}
\hline \multirow{2}{*}{ Host } & \multirow{2}{*}{$\begin{array}{l}\text { Number } \\
\text { of indi- } \\
\text { viduals }\end{array}$} & \multicolumn{2}{|c|}{ Females } & \multicolumn{2}{|c|}{ Males } & \multirow{2}{*}{$\begin{array}{c}\text { Females } \\
\text { and } \\
\text { males } \\
\text { (mean) }\end{array}$} \\
\hline & & Range & Mean & Range & Mean & \\
\hline \multicolumn{7}{|c|}{ Weight } \\
\hline $\begin{array}{l}\text { Almond.... } \\
\text { Walnut..... } \\
\text { Orange..... }\end{array}$ & $\begin{array}{r}17 \\
15 \\
2\end{array}$ & $\begin{array}{l}0.0245-0.0438 \\
0.0226-0.0412 \\
\ldots \ldots\end{array}$ & $\begin{array}{l}0.0337 \pm 0.005 \\
0.0323 \pm 0.007 \\
0.0419\end{array}$ & $\begin{array}{l}0.0155-0.0342 \\
0.0184-0.0420 \\
\ldots \ldots\end{array}$ & $\begin{array}{l}0.0250 \pm 0.005 \\
0.0274 \pm 0.010 \\
0.0284\end{array}$ & $\begin{array}{l}0.0295 \\
0.0298 \\
0.0351\end{array}$ \\
\hline \multicolumn{7}{|c|}{ Length } \\
\hline $\begin{array}{l}\text { Almond... } \\
\text { Walnut.... } \\
\text { Orange.... }\end{array}$ & $\begin{array}{r}17 \\
15 \\
2\end{array}$ & $\begin{array}{l}8.25-10.75 \\
8.25-10.50 \\
\ldots \ldots\end{array}$ & $\begin{array}{r}9.69 \pm 0.66 \\
9.36 \pm 1.30 \\
10.50\end{array}$ & $\begin{array}{l}7.50-9.50 \\
8.00-10.00 \\
\ldots .\end{array}$ & $\begin{array}{l}8.72 \pm 0.65 \\
9.00 \pm 0.69 \\
9.25\end{array}$ & $\begin{array}{l}9.21 \\
9.18 \\
9.87\end{array}$ \\
\hline
\end{tabular}

\section{FIELD BIOLOGY}

Field observations were initiated in 1951 and continued through 1953 near Tracy and Merced, California, where known infestations existed on almond, walnut, and fig.

\section{Habits}

The eaterpillars had no difficulty entering sound nuts after the hulls cracked. In the case of almonds, they were able to penetrate the shell of mature nuts, while with mature sound walnuts, entry was gained at the stem end or through the suture. An account of this insect on almond was given by Bacon and Wade (1954). Ortega (1950) reported that in walnuts the navel orangeworm also enters through the holes left by codling-moth larvae or through the pithy tissue at the basal suture. The fullest account of the insect on this erop is that given by Michelbacher and Davis (1961).

In almonds, larvae and larval feedings were observed not only on the meats but also between the hull and shell. In the latter location, the larvae can undoubtedly complete their development because fourth- and fifthinstar individuals, along with pupae, were observed in this area, while no feeding on the meats could be detected.

When feeding on the meats of both almonds and walnuts, some larvae rasped the surface while others bored deeply into the meat, being detectable only by the minute frass observed at the entry. Where large larvae were observed, there was always a great deal of frass and webbing was very pronounced. The webbing was often so profuse as to completely hide any remaining meat.

On completing their development, the larvae spin a silken cocoon and a tube to an exit hole in the shell or hull, so that they can leave freely on becoming adults.

Single larvae in an almond were not uncommon, but generally there were several. The largest number taken in a single almond was seventeen, while 
in walnut it was forty-nine. The greater number found in walnuts is undoubtedly explained by the fact that they contain a greater food supply and thus can support a higher population.

In those samples where larvae were observed, it was not uncommon to find dead ones. Many of these had died from causes other than predators or parasites. They showed no evidence of having been fed upon, and specimens submitted to the Department of Insect Pathology at the University of California were reported to be disease-free.

There was no diapause in any of the stages from egg through adult because all stages observed were active if alive. Individuals collected in the field during the winter immediately went into the next stage of development when introduced into a warmer temperature.

\section{Activity in Almonds}

A study of adult activity was attempted through use of bait pans, as previously described under "Experimental Methods." (See p. 138.) The baits employed in this experiment were: (1) Standard diamalt bait (Dethier, 1947), consisting of 1.2 pint of diamalt, 1.2 cake of compressed yeast, and 22.8 pints of water. (2) Terpinyl acetate diamalt bait, consisting of 1 pint of diamalt, 6 tablespoons of terpinyl acetate (stock), one-half cake of compressed yeast, and water to make 2.5 gallons. (3) Stock terpinyl acetate, consisting of $52 \mathrm{cc}$. of terpinyl acetate, 12 grams of bentonite, and water to make 1 pint. (4) Orange-juice bait, consisting of one-half cake of yeast and orange juice and water in a 50:50 proportion. (5) Vinegar bait, consisting of vinegar and water in a 50:50 proportion. The bait pans were distributed throughout the orchard and were serviced every three or four days from April to July. All results were negative, with no navel orangeworm adults being taken. It should be noted, however, that Armitage (1944) and Keifer (1947) reported that navel orangeworm adults were repeatedly taken in oriental fruit moth traps which contained standard diamalt bait.

Following the above failure, experiments with dried bait in traps were employed, using the following attractants: (1) Old nuts (meats, shells, and hulls). (2) Nut meats. (3) Nut meats and cyanide. These traps were serviced at three-day intervals, from July through the middle of August, with no navel orangeworm adults being taken. (See p. 139.)

Because light traps require daily attention and the distance to travel to and from the orchard was prohibitive, they were not employed in this study; however, they may be worthy of mention here. The Federal Bureau of Entomology recorded one adult being taken in a light trap near Tempe, Arizona, on October 4, 1920 (Mote, 1922). One adult was taken on July 8, 1953 , in a kerosene lamp used in potato tuber moth experiments near San Juan Bautista, California. The trap which captured the moth was in the vicinity of a young walnut orchard, and although the traps were maintained well into September, no further adults were taken. ${ }^{\circ}$ Glick (1922) stated that J. H. O'Dell ran two light traps in the Salt River Valley area

\footnotetext{
${ }^{6}$ These experiments were conducted hy Dr. O. G. Bacon, of the Department of Entomology and Parasitology, University of California, Berkeley.
} 
TABLE 13

SEASONAL PREVALENCE OF NAVEL ORANGEWORM ON IXL ALMOND STICK-TIGHTS NEAR TRACY, CALIFORNIA

\begin{tabular}{|c|c|c|c|c|c|c|c|c|c|}
\hline \multirow{2}{*}{$\begin{array}{c}\text { Survey } \\
\text { date }\end{array}$} & \multirow{2}{*}{ 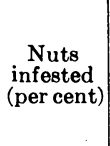 } & \multirow{2}{*}{ Eggs } & \multicolumn{5}{|c|}{ Number of larvae per instar } & \multirow{2}{*}{ Pupae } & \multirow{2}{*}{$\begin{array}{c}\text { Total } \\
\text { larvae } \\
\text { and } \\
\text { pupae }\end{array}$} \\
\hline & & & First & Second & Third & Fourth & $\begin{array}{l}\text { Fifth } \\
\text { and } \\
\text { sixth }\end{array}$ & & \\
\hline Nov. 15,1952 & 22.0 & 0 & .1 & 4 & 3 & 4 & 1 & 1 & 14 \\
\hline Dec. 13,1952 . & 23.1 & $\mathbf{0}$ & 1 & 5 & 4 & 4 & 0 & 1 & 15 \\
\hline Jan. $16,1953$. & 22.3 & 0 & 1 & 4 & 5 & 5 & 1 & 1 & 17 \\
\hline Jan. $28,1953 \ldots$ & 21.7 & $\mathbf{0}$ & $\mathbf{0}$ & 9 & 7 & 8 & $\mathbf{0}$ & 1 & 25 \\
\hline Feb. 5, 1953. & 24.0 & $\mathbf{0}$ & 0 & 10 & 16 & 20 & 0 & 1 & 47 \\
\hline Feb. $12,1953$. & 18.8 & 0 & 1 & 6 & 8 & 6 & 3 & $\mathbf{0}$ & 24 \\
\hline Feb. $19,1953$. & 31.0 & $\mathbf{0}$ & 0 & 9 & 22 & 12 & 12 & 1 & 56 \\
\hline Feb. $25,1953$. & 27 & $\mathbf{0}$ & 0 & 5 & 13 & 9 & 7 & 4 & 38 \\
\hline March 4, 1953. & 30 & $\mathbf{0}$ & 0 & 4 & 18 & 15 & 11 & 1 & 49 \\
\hline March 11, 1953. & 33 & 0 & 0 & 2 & 21 & 17 & 14 & 4 & 58 \\
\hline March 18, 1953. . & 37 & 0 & 0 & 3 & 14 & 18 & 26 & 4 & 65 \\
\hline March 25, 1953. & 34 & 0 & 0 & 2 & 8 & 16 & 24 & 4 & 54 \\
\hline April $1,1953$. & 33 & 3 & 0 & 0 & 7 & 14 & 21 & 6 & 48 \\
\hline April $15,1953$. & 23 & 5 & 0 & 0 & 5 & 7 & 9 & 6 & 27 \\
\hline April $22,1953 \ldots$ & 26 & 40 & 2 & 0 & 8 & 6 & 6 & 5 & 27 \\
\hline April $29,1953$. & 44 & 148 & 4 & 0 & 8 & 6 & 12 & 16 & 46 \\
\hline May $6,1953$. & 18 & 88 & 5 & 2 & 5 & 3 & 4 & 4 & 23 \\
\hline May $13,1953$. & 33 & 57 & 36 & 10 & 3 & 6 & 12 & 14 & 81 \\
\hline May $20,1953$. & 26 & 62 & 24 & 20 & 5 & 2 & 7 & 14 & 72 \\
\hline May $27,1953$. & 44 & 50 & 21 & 73 & 24 & 4 & 7 & 15 & 144 \\
\hline June $10,1953$. & 38 & 49 & 9 & 24 & 52 & 26 & 7 & 7 & 125 \\
\hline June $17,1953$. & 40 & 33 & 14 & 14 & 21 & 19 & 11 & 3 & 79 \\
\hline June 23,1953 & 37 & 45 & 12 & 22 & 35 & 39 & 13 & 1 & 122 \\
\hline June 30,1953 & 38 & 21 & 8 & 12 & 20 & 20 & 21 & 5 & 86 \\
\hline July 11,1953 & 36 & 19 & 4 & 5 & 9 & 15 & 11 & 22 & 66 \\
\hline July $18,1953$. & 39 & 74 & 8 & 7 & 14 & 19 & 15 & 21 & 84 \\
\hline July $25,1953 \ldots$ & 40 & 25 & 4 & 7 & 12 & 10 & 12 & 21 & 66 \\
\hline July $31,1953$. & 41 & 30 & 5 & 9 & 8 & 10 & 7 & 10 & 49 \\
\hline Aug. 8,1953 . & 38 & 20 & 12 & 15 & 22 & 12 & 7 & 8 & 76 \\
\hline Aug. 14,1953 . & 31 & 18 & 11 & 12 & 9 & 2 & 6 & 8 & 48 \\
\hline Aug. 20,1953 . & 34 & 28 & 4 & 7 & 18 & 8 & 3 & 8 & 48 \\
\hline Aug. $27,1953$. & 36 & 20 & 7 & 7 & 9 & 8 & 8 & 4 & 43 \\
\hline Sept. $4,1953$. & 38 & 16 & 13 & 12 & 5 & 11 & 9 & 8 & 58 \\
\hline Sept. $11,1953$. & 38 & 17 & 3 & 11 & 12 & 4 & 9 & 5 & 44 \\
\hline Sept. $26,1953$. & 42 & 13 & 10 & 7 & 14 & 14 & 10 & 5 & 60 \\
\hline Oct. 12,1953 . & 39 & 11 & 9 & 8 & 12 & 10 & 12 & 6 & 57 \\
\hline
\end{tabular}

of Arizona from May 26 to July 25 without taking navel orangeworm adults. Later in his paper, he mentioned that a number of adults were taken in light traps set in orange groves.

Recent studies conducted by members of the Department of Entomology and Parasitology, University of California, Berkeley, have demonstrated that adults are attracted to "black light" (ultraviolet).

Seasonal Population Trends. The almond orchard selected was located near Tracy, California, and had a history of navel orangeworm infestation. Observations were begun on November 15, 1952, and were continued through October 12, 1953. The degree of infestation was studied by observing the presence of eggs, larvae, and pupae found in nut samples which were collected at intervals, as described under "Experimental Methods." (See p. 139.) 
Only the soft-shell varieties were infested. Those present in the orchard were IXL, Ne Plus Ultra, and Nonpareil. Of these, the most serious infestation occurred in IXL. For this reason, most of the investigations were conducted with this variety. It was the only variety in which a large number of almonds remained on the trees following harvest. These almonds are referred to as "stick-tights," and beyond a doubt are associated with the serious infestation that occurs in the IXL variety. The stick-tights are very important in carrying the navel orangeworm through the winter. For a portion of the year, they constitute the only food supply readily available. However, even at those times when nuts of other varieties were present, the infestation continued to be higher in the IXL's, despite the fact that the former were planted in adjacent rows. This would seem to indicate that IXL is the preferred variety.

Because stick-tights are present in the trees throughout the year, they furnish the best means of following the seasonal activity of the insect. Nut samples were gathered at intervals of one to three weeks, and the state of development of individuals found in the samples was recorded. The results are given in table 13 . It is clearly shown that the navel orangeworm successfully passes the winter in both the larval and pupal stages. During the coldest portion of the year, there is apparently no reproduction. This was made evident by the fact that from November 15 through March 25, no eggs were recovered in any of the samples taken. The absence of egg laying is reflected in the number of first-instar larvae present. A few were encountered in early winter, but none were found in late winter and early spring. Those present were either killed by cold or passed into the second instar. Second-instar larvae were present throughout the winter, but none were taken in four surveys conducted in early spring. It is assumed that second-stage larvae successfully molted into the third instar. All other larval stages were observed during the winter and early spring. With the advance of the season from late fall to early spring, there was a tendency for the later instars to become more abundant. Thus, throughout the cold portion of the year, there was a progression of fewer younger to more older larvae and pupae.

Eggs were encountered on April 1, and from then on a great deal of activity was noted. During the spring, summer, and early fall, there were a number of generations. However, there was no indication of definite broods, and it can be concluded that there was an overlapping of generations.

Infestation that occurred in nuts gathered from the ground in the case of the IXL variety is recorded in table 14. The information supports that given for the stick-tights but is not nearly so complete. The destruction of nuts on the ground owing to rain, irrigation, and cultivation made it difficult to obtain adequate samples with the advance of the season. Furthermore, the results were influenced to some extent by the few stick-tights which dropped from time to time.

Although detailed studies were not conducted in regard to the dropped nuts of the other varieties, enough samples were examined to determine that the trend of the infestation was similar to that shown for the IXL variety.

Nuts from a dead IXL tree were examined during the winter and spring. 
TABLE 14

SEASONAL PREVALENCE OF NAVEL ORANGEWORM ON IXL ALMONDS GATHERED FROM THE GROUND NEAR TRACY, CALIFORNIA

\begin{tabular}{|c|c|c|c|c|c|c|c|c|c|}
\hline \multirow{2}{*}{$\begin{array}{c}\text { Survey } \\
\text { date }\end{array}$} & \multirow{2}{*}{$\begin{array}{c}\text { Nuts } \\
\text { infested } \\
(\text { per cent) }\end{array}$} & \multirow[b]{2}{*}{ Eggs } & \multicolumn{5}{|c|}{ Number of larvae per instar } & \multirow[b]{2}{*}{ Pupae } & \multirow{2}{*}{$\begin{array}{l}\text { Total } \\
\text { larvae } \\
\text { and } \\
\text { pupae }\end{array}$} \\
\hline & & & First & Second & Third & Fourth & $\begin{array}{l}\text { Fifth } \\
\text { and } \\
\text { sixth }\end{array}$ & & \\
\hline Nov. 15,1952 . & 13.2 & 0 & $\mathbf{0}$ & 4 & 8 & 4 & 0 & 0 & 16 \\
\hline Dec. 13,1952 . & 12.9 & 0 & $\mathbf{0}$ & 3 & 7 & 6 & 1 & 1 & 18 \\
\hline Jan. $16,1953$. & 13.6 & 0 & 0 & 5 & 9 & 5 & 0 & 1 & 20 \\
\hline Jan. 28,1953 . & 10.2 & $\mathbf{0}$ & $\mathbf{0}$ & 3 & 6 & 5 & 0 & 0 & 14 \\
\hline Feb. $5,1953$. & 24.7 & 0 & 0 & 2 & 8 & 15 & 0 & 0 & 25 \\
\hline Feb. $12,1953$. & 28.3 & 0 & 0 & 5 & 11 & 1 & 7 & 0 & 24 \\
\hline Feb. $19,1953$. & 29.2 & 0 & 0 & 3 & 15 & 14 & 15 & 2 & 49 \\
\hline Feb. $25,1953$. & 22.0 & 0 & 0 & 3 & 4 & 5 & 3 & 0 & 15 \\
\hline March 4, 1953. & 22.0 & 0 & 0 & 0 & 4 & 5 & 5 & 0 & 14 \\
\hline March 11, 1953. & 22.0 & 0 & 0 & 0 & 6 & 6 & 5 & 1 & 18 \\
\hline March $18,1953$. & 37.0 & 0 & 0 & 1 & 5 & 7 & 7 & 3 & 23 \\
\hline March 25, 1953 & 37.0 & 0 & 0 & 0 & 11 & 10 & 19 & 8 & 48 \\
\hline April $1,1953$. & 21.0 & 0 & 0 & 0 & 2 & 6 & 4 & 1 & 13 \\
\hline April $15,1953$. & 25.0 & 3 & 0 & 0 & 2 & 5 & 2 & 2 & 11 \\
\hline April $22,1953$. & 23.0 & $\mathbf{0}$ & 0 & 0 & 0 & 4 & 4 & 2 & 10 \\
\hline April $29,1953$. & 26.0 & 1 & 0 & 0 & 0 & 1 & 5 & 7 & 13 \\
\hline May $6,1953$. & 15.0 & 0 & 0 & 0 & 0 & 0 & 0 & 2 & 2 \\
\hline May $13,1953$. & 19.0 & 1 & 1 & 0 & 0 & 1 & 1 & 5 & 8 \\
\hline May $20,1953$. & 09.0 & 0 & 0 & 0 & 0 & 0 & 2 & 1 & 3 \\
\hline May 27,1953 . & 11.0 & 0 & 0 & 0 & 0 & 0 & 1 & 0 & 1 \\
\hline June $10,1953 \ldots$ & 08.0 & 0 & 0 & 1 & 0 & 1 & 1 & 0 & 3 \\
\hline
\end{tabular}

The data are recorded in table 15 , and tend to parallel the information given for stick-tights. It is interesting to note that many nuts were infested in which there was no evidence of the hull eracking.

Population Trend in 1953 Season's Crop. The 1953 IXL crop was progressively sampled, from a short time after petal fall until the nuts were harvested-March 11 through September 26. No evidence of infestation was found until August 7, when one first-instar larva was noted. At this time, the hulls had split and many of them were drying. From this date on, the incidence of infestation in the season's crop progressively increased until it

TABLE 15

SEASONAL PREVALENCE OF NAVEL ORANGEWORM ON IXL ALMONDS FROM A DEAD TREE NEAR TRACY, CALIFORNIA

\begin{tabular}{|c|c|c|c|c|c|c|c|c|c|}
\hline \multirow{2}{*}{$\begin{array}{c}\text { Survey } \\
\text { date }\end{array}$} & \multirow{2}{*}{$\begin{array}{c}\text { Nuts } \\
\text { infested } \\
\text { (per cent) }\end{array}$} & \multirow{2}{*}{ Eggs } & \multicolumn{5}{|c|}{ Number of larvae per instar } & \multirow{2}{*}{ Pupae } & \multirow{2}{*}{$\begin{array}{l}\text { Total } \\
\text { larvae } \\
\text { and } \\
\text { pupae }\end{array}$} \\
\hline & & & First & Second & Third & Fourth & $\begin{array}{l}\text { Fifth } \\
\text { and } \\
\text { sixth }\end{array}$ & & \\
\hline Jan. $16,1953 .$. & 27.0 & $\mathbf{0}$ & $\mathbf{0}$ & 17 & 13 & 11 & 0 & 4 & 45 \\
\hline Jan. $28,1953$. & 5.0 & 0 & 0 & 0 & 5 & 3 & $\mathbf{0}$ & 0 & 8 \\
\hline Feb. 5, 1953.. & 6.0 & 0 & $\mathbf{0}$ & 3 & 2 & 1 & $\mathbf{0}$ & 0 & 6 \\
\hline Feb. 12, 1953.. & 5.0 & 0 & 0 & 1 & 4 & 2 & 0 & 0 & 7 \\
\hline Feb. $19,1953$. & 77.0 & 0 & 0 & 0 & 4 & 7 & 8 & 0 & 19 \\
\hline Feb. 25, 1953.. & 30.0 & 0 & 0 & 1 & 4 & 4 & 5 & 0 & 14 \\
\hline March 4, 1953.. & 2.0 & 0 & 0 & 1 & 0 & 0 & 0 & 1 & 2 \\
\hline
\end{tabular}


reached 7 per cent at the final survey, which was conducted September 26 . No eggs were detected until August 27. They must have been present before this, but probably were not encountered because of the low infestation.

\section{Activity in Walnuts}

The orchard in which the observations were made was located near Merced, California, and consisted of Eureka, Franquette, Concord, and Payne varieties. Activity of the caterpillars in nuts on the ground and the few remaining on the trees was studied from October 15 through March 7. Samples of these nuts were taken into the laboratory and examined for the pest. The Concord and Payne varieties were the most heavily infested, while the infestation in the Eureka and Franquette varieties was relatively light. There was little change in the per cent of infested nuts during the period the study was conducted.

The fact that Concord and Payne were the varieties most heavily infested with codling moth may support the statement of Ortega (1950), in which he indicated that the navel orangeworm enters nuts following codling-moth larvae. In several instances, infestation occurred in nuts that had first been attacked by the codling moth, although the pest freely entered sound nuts. Michelbacher and Ross $(1955,1957)$ and Michelbacher (1956) reported that attacks by the codling moth result in an increase in navel orangeworm infestations in sound nuts at harvest.

Michelbacher and Davis (1961) showed that the development of serious infestations in walnut orchards is encouraged by failure to control the codling moth, the presence of nuts infected with arrested walnut blight, and the prevalence of other unsound nuts. During the development of the crop, the navel orangeworm breeds in these nuts, so that by harvest a potentially large moth population may be present to infest sound nuts after the husks crack. Other influencing factors having a bearing on infestation, as pointed out by the above workers, include sanitation, size of planting, temperature, moisture, rapidity of harvest, speed of drying the crop, and promptness of fumigation. They also mentioned the fact that some infestation may arise from moths that migrate into the orchard from other hosts.

It is assumed that the life history of the navel orangeworm is the same on walnuts as it is on almonds, and that the stick-tights in the grove serve to perpetuate infestation.

\section{Activity in Figs}

Figs in the immediate vicinity of the Merced walnut orchard had an infestation which ran about 3 per cent during October and November. The infestation occurred in fruit that had been left on the trees. All immature stages of the navel orangeworm except eggs were found.

Figs, if left in the orchard, can undoubtedly serve as an overwintering host and act as a source of infestation for the following season.

\section{Adult Activity}

During the course of this study, only two adults were observed in the field, and those quite by accident. One was noticed flying among almond trees and the other was found on a walnut sack. Their flight habits indicated that they 
are not strong fliers, for in the field, as in cages, the flights were very short in duration and very irregular in direction. Michelbacher and Davis (1961), who conducted their investigations in walnut orchards, noted that under conditions of heavy infestation, adults may be seen frequently at harvest time.

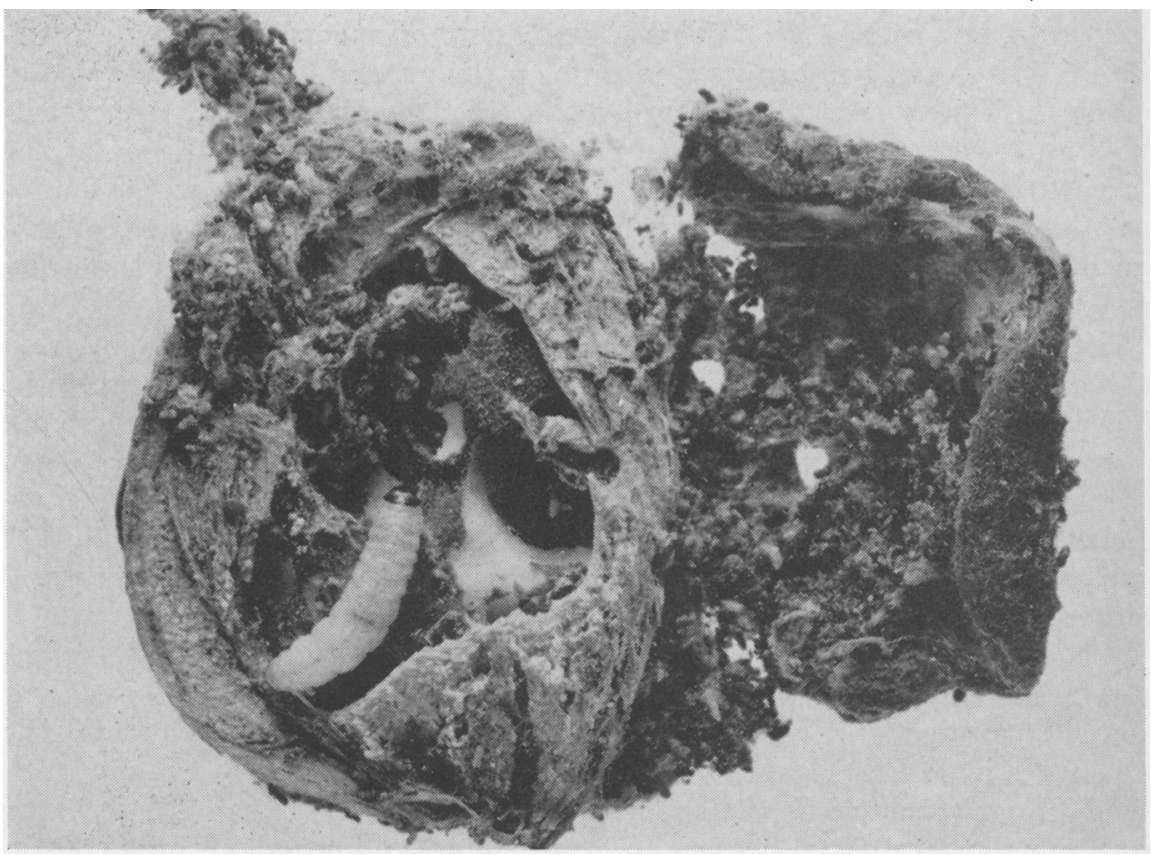

Fig. 13. Damage to almond meats caused by feeding of navel orangeworm larvae. $(\times 3$.

\section{NATURE OF INJURY}

Feeding damage inflicted by larvae to almonds and walnuts appears the same in the field as it does in storage. The meats (figs. 13 and 14) are rasped and tunneled. There are innumerable fecal pellets present, and because of the caterpillars' proclivity to web so prolifically, there is always an abundance of silken threads.

The threads are interspersed with the frass, creating a very tangled covering which may afford some protection to the larvae in nature. The amount of frass and the degree of webbing are dependent upon the number of larvae present and the stage of development, although one larva is capable of producing a great deal of both.

In storage, the larvae have a tendency to leave the nut and move about. During this wandering, they spin a great deal of silk, tying large groups of nuts together, as shown in figure 15. This type of damage can create considerable trouble when the nuts are processed. In moving about, it is also possible for one larva to inflict damage to more than one nut.

In the case of walnuts, an infestation by the navel orangeworm can be most annoying because caterpillars can gain entry into the nuts without leaving 


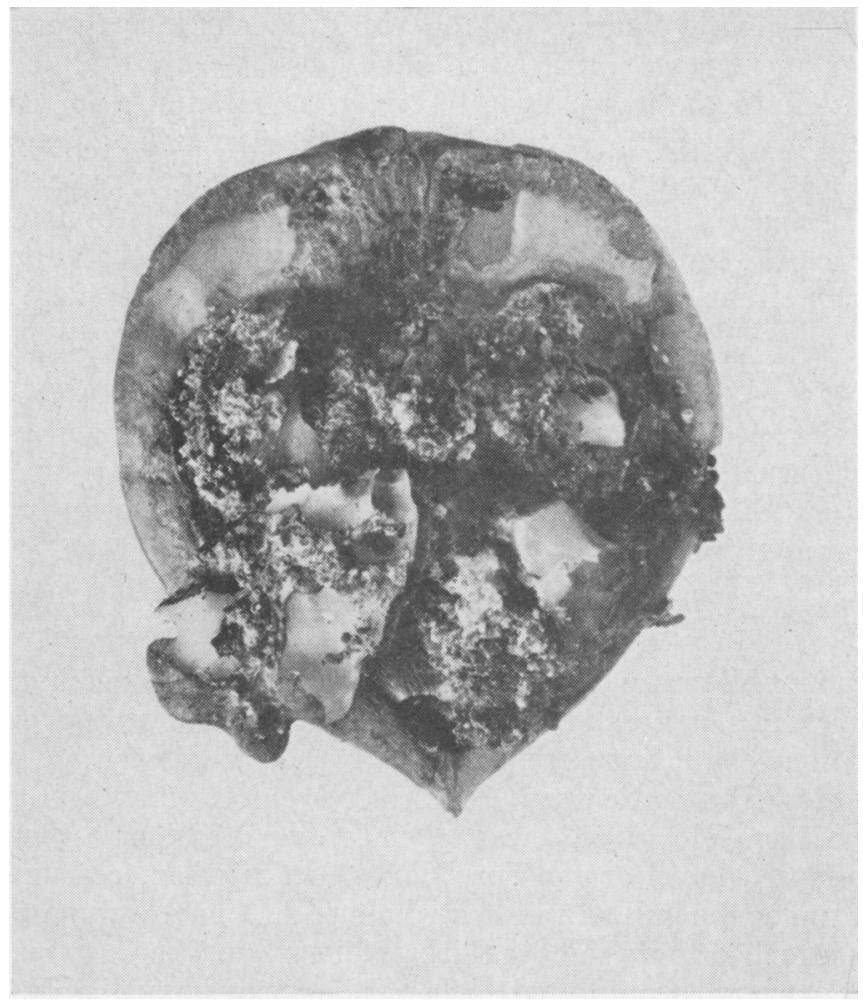

Fig. 14. Damage to walnut meats caused by feeding of navel orangeworm larvae. $(\times 2$. $)$

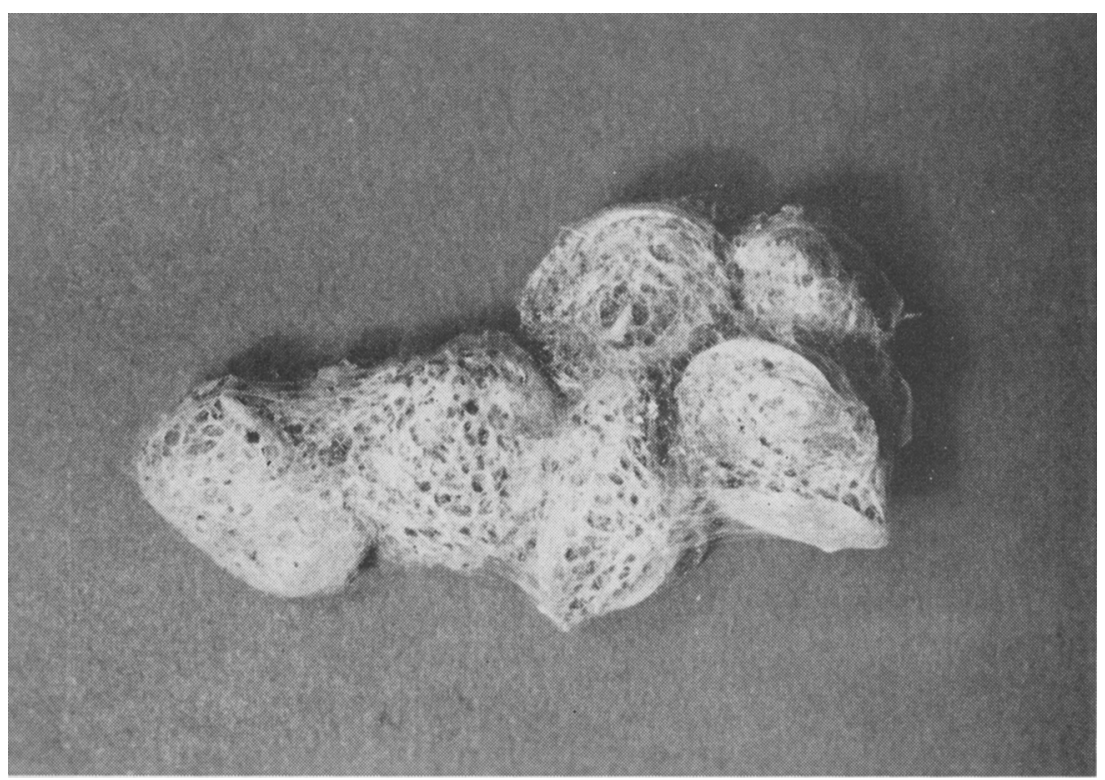

Fig. 15. Typical webbing on almonds caused by navel orangeworm larvae. 
any evidence of having done so. The following statement has been taken from Michelbacher and Ortega (1958): "Because the larvae are unable to penetrate the nuts until the husks begin to crack, they do not stain the shell. In this, the infestation resembles that of the filbertworm. The absence of shellstaining makes it very difficult to determine by external appearance if a nut is infested. Because of this characteristic, the only sure way to detect infestation is to crack the nut open. The hidden nature of the infestation creates a very annoying situation with walnuts used in the in-shell trade."

\section{CONTROL}

When an insect species becomes a primary pest and inflicts economic damage to a crop, measures must be taken to suppress its population density if natural factors fail to do so. In view of this fact, the following methods of control were investigated.

\section{Natural Control}

Parasites and predators which were actually observed attacking the navel orangeworm were not great in number. Many predators were observed in close association with it but were not actually seen feeding.

A new species of parasitic wasp, Perisierola breviceps (family Bethylidae), described by Krombein (1954), was taken on two occasions cocooned on the side of a collapsed navel orangeworm larva. On another occasion, an adult was present under the hull of an infested almond. A navel orangeworm larva with an egg attached to its side was situated near-by. The wasp was removed and another larva was presented to her. The wasp immediately paralyzed the larva by stinging it on the dorsum behind the head. No immediate attempt was made by the parasite to oviposit. She primped and cleaned her legs and antennae profusely, and at times appeared to be chewing on the incapacitated larva. Chewing always took place laterally and on the abdomen. There were also relatively long periods during which the wasp straddled the larva with no further apparent action. Oviposition (fig. 16) finally took place two hours after the introduction of the larva. The egg was deposited externally and longitudinally on one side of the paralyzed larva. The egg, at approximately $25^{\circ} \mathrm{C}$., underwent a four-day incubation period. Two days after hatching, the parasite larva had completely devoured the internal contents of the host larva. Only the integument remained. After devouring the caterpillar, it attempted to spin a cocoon. The attempt was not successful, and after two days the larva transformed to a pupa without forming a cocoon. The white pupa turned black approximately seven days after pupation, and the adult emerged three days after the color change. The total life cycle from egg to adult was approximately eighteen days.

Another parasite definitely attacking navel orangeworm larvae is an ichneumonid wasp, Mesostanus gracilis Cr. It was observed in a cocoon in the hollowed integument of a navel orangeworm larva.

Ortega (1950) reported that Microbracon hebetor (Say) (= Bracon hebetor Say-family Braconidae) was reared from larvae of the navel orangeworm in southern California. 
During laboratory rearing, a predaceous laelaptid mite, Blattisocius tineivorus (Oudemans), ${ }^{7}$ caused considerable annoyance by piercing eggs with its mouth parts and removing the contents. Adult moths were also observed to be hosts of this mite. In one case, thirty-four adult mites were found on one female. They were located under the wings and on the dorsal prothoracic region. So far as could be determined, the mites were not interfering with the activity of the adults. According to Dr. Pritchard, this species of mite

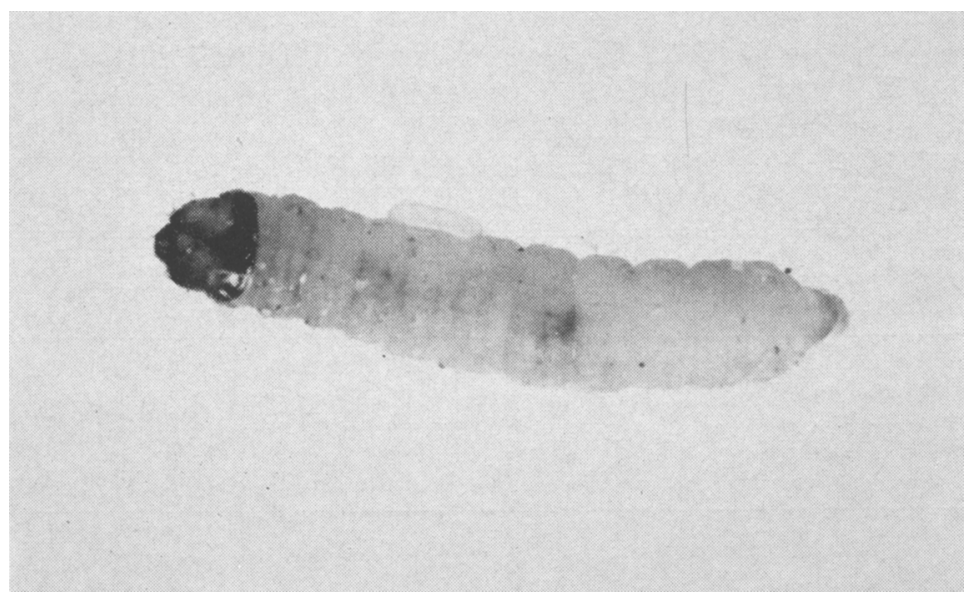

Fig. 16. Egg of Pcrisicrola breviceps Krombein on larva of the navel orangeworm. $(\times 5$.

has never been taken in nature, but only in laboratories and buildings containing stored-food pests. The building in which these experiments were conducted had been used for rearing stored-food insects. However, there is no record of these mites ever having been in the building, and after the rearing bottles had been sterilized, the mites were not encountered again.

A black thrips with white wing veins which was determined by Dr. S. F. Bailey of the University of California as the black hunter thrips, Leptothrips mali (Fitch), was very numerous in the field on almonds throughout the warmer months. Although it was never actually observed feeding on navel orangeworm eggs or larvae, it is very possible that it will attack the eggs. According to Bailey (1940), it is a common and widely distributed predator in North America. He stated that it is a solitary species, very active, but with a low reproductive potential. Bailey further stated that Jones and Plank considered it to be predaceous on lepidopterous eggs, and that these workers reported that 18 per cent of 122 peach-twig borer eggs showed evidence of having been preyed upon. Sharp (1938) reported it attacking eggs of the pecan nut casebearer, and Fernald (1892) suspected it of being predaceous on gypsy-moth eggs. The importance of this insect as an egg predator is not fully demonstrated, but it is possible that in the field it may destroy a considerable number of navel orangeworm eggs.

\footnotetext{
${ }^{7}$ Determined by Dr. A. E. Pritchard, of the Department of Entomology and Parasitology, University of California, Berkeley.
} 
Michelbacher and Davis (1961) reported the clerid, Cymatodera ovipennis Lec., a predator of navel orangeworm larvae, as exhibiting some promise. They also found the common fungus, Beauveria bassiana (Bals.), attacking the larvae.

\section{Chemical Control}

Orchards. There is no known spray program which will directly control the navel orangeworm, although Michelbacher and Ross (1955), working with walnuts, showed that infestation by the navel orangeworm is reduced if the codling moth is effectively controlled. Similar results were noted by Michelbacher and Ortega (1958) and Michelbacher and Davis (1961).

TABLE 16

TREATMENTS AND INFESTATION OF THE NAVEL ORANGEWORM AT HARVEST IN AN ALMOND ORCHARD NEAR MERCED, CALIFORNIA

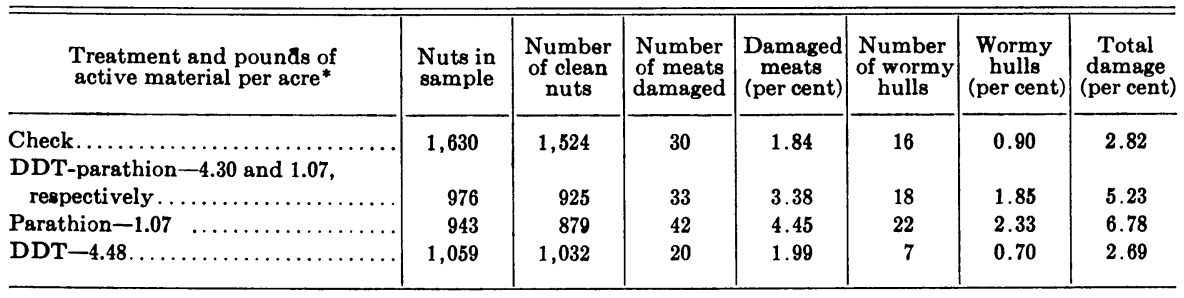

* Applied August 2, 1954.

In 1954, a test was designed to determine whether or not DDT as a 50 per cent wettable powder or parathion as a 25 per cent wettable powder or the combination of these two materials would control the navel orangeworm on almond.

An almond orchard of the Nonpareil variety near Merced, California, which had a history of this insect was selected for the experiment. Each plot consisted of 125 trees, except for the check area which comprised the remainder of the orchard. None of the trees had had any insecticides applied to them during that season.

At the time the applications were made, the hulls of the nuts were splitting and the nuts were at the stage of development where navel orangeworm larvae would soon be entering them.

The DDT was applied at 4.48 pounds active material in 450 gallons of water per acre. The parathion was applied at 1.07 pound active material in 425 gallons of water per acre. In the DDT-parathion combination, 4.30 and 1.07 pounds of active materials, respectively, were applied in 425 gallons of water per acre.

Nut samples were taken at harvest and the numbers of infested nuts and infested hulls were recorded.

The results of this experiment are given in table 16. It is clearly evident that DDT was no better than the checks, while in the parathion plot the number of wormy nuts was actually higher than the check. When the DDTparathion combination was used, the per cent of infested nuts was higher than in the DDT plot but lower than in the parathion plot.

It would appear, then, that DDT had no effect whatsoever upon navel 
orangeworm larvae, while parathion actually increased the degree of infestation. The situation could possibly have developed through the destruction of natural enemies.

Packing Houses. Gerhardt et al. $(1951,1952)$ reported that satisfactory control of fourth- and fifth-instar navel orangeworm, in whole walnuts, could be obtained by fumigating at atmospheric pressure for a two-hour exposure with methyl bromide at two pounds per thousand cubic feet when the nuts were in loosely woven sacks. When the nuts were in sealed, double-walled cellophane bags, satisfactory control could not be obtained with higher dosages, except probably with an exposure of more than eight hours.

They further showed that the nuts absorb bromine and concluded that walnuts which have been subjected to methyl bromide fumigation may be expected to show high bromine residues.

\section{Cultural Control}

As discussed earlier, the navel orangeworm is present in stick-tights throughout the year. It seriously attacks the current crop only after the hulls have split. Therefore, early and complete harvest of the nuts is desirable, because the longer the nuts are left on the tree, the greater is the opportunity for them to become infested.

Sources of overwintering individuals should be eliminated. This means that stick-tights should be removed from the trees and destroyed. Nuts left lying on the ground should be destroyed by plowing or other suitable means. Culls and the waste products around dehydrators, hullers, and other buildings should be destroyed by burning or plowing. Everything possible should be done to break the food chain before nuts of the current crop are in a stage susceptible to infestation.

If at all possible, these measures should be practiced on a community basis, because reinfestation from neighboring orchards can occur.

With walnuts, at least, it is important to produce nuts free of defects, for certain of these are important as furnishing breeding sources for the pest during the development of the crop. The factors involved have been considered in the section, "Activity in Walnuts." (See p. 161.)

When a crop is known to be infested at harvest, every effort should be made to have it fumigated before placing it in storage. In this way, the incidence of infestation may be kept to a minimum.

\section{SUMMARY}

The navel orangeworm, Paramyelois transitella (Walker), belongs to the family Phycitidae (Pyralididae). It was first described by Dyar in 1915 from specimens taken in Mexico. The first individual recorded from the United States was collected near Tempe, Arizona, in 1920. In 1933, larvae of this moth were collected at Stillwater, Oklahoma; in 1940, in Georgia; and in 1942, it was noted for the first time in California.

In California, the spread of this insect has been rapid, and it is now known to exist in most of the nut- and fruit-producing areas.

The navel orangeworm has been found in many fruits and nuts, and until recently was considered a scavenger. However, it is actually a primary pest 
of almonds and walnuts because the larvae are capable of attacking sound nuts after the hulls split.

The adults of the navel orangeworm are silver-gray snout moths, their forewings ornamented with black, irregularly narrow to broadly wavy lines. The females are larger than the males.

The egg is elliptical or oval in outline and is flattened dorsoventrally. It has numerous ridgelike markings on the surface.

The larvae, upon hatching, are reddish in color, but after the first molt take on a lighter hue which normally persists throughout the larval period. The color of the larvae is influenced by age and the food on which they develop. In all larval instars, the sclerotized areas around seta $P$ on the mesothorax are in the form of a crescent with the open end dorsad. The sclerotized area around seta $\boldsymbol{P}$ of the eighth abdominal segment is normally crescentshaped but occasionally is closed, forming a circle.

The various larval instars may be determined by measuring the length and width of the head capsules. The head capsule increases in size with each molt, and under a given set of conditions there is no overlap. Instar determination may also be made by using the average number of crotchets on the prolegs, because the number of crotchets increases with each molt.

The pupae are dark brown in color with very prominent sutures. The genital openings are very evident on both female and male pupae.

In this study, female pupae consistently weighed more and were longer than the males. Pupal weights increased with an increase in $\mathrm{rh}$. but decreased with an increase in temperature above $25^{\circ} \mathrm{C}$. Pupal lengths were influenced by $\mathrm{rh}$. and temperature, as were the weights.

Adults showed a tendency to live longer at $25^{\circ} \mathrm{C}$. and 75 per cent rh. Their lives were shortened at higher temperatures and lower rh.

The adult moths were very reluctant to mate indoors, although sporadic mating did occur. Mating outdoors was much more frequent and always occurred during the early-morning hours. The period of copulation actually extended from two to four hours; in one instance, to nine hours.

Mating occurred immediately after emergence, up to four days later.

Females oviposited whether they had been fecundated or not. Normally, the highest egg deposition took place on the first day of oviposition and decreased as the number of days increased. Unfertilized females laid fewer eggs than fertilized individuals, and females fertilized the first or second day after emergence deposited more eggs than did those fertilized the third or fourth day.

Eggs deposited in captivity were usually found in rather large clusters, whereas eggs deposited in the field were normally laid singly. Eggs in the field were usually found on the nuts, nut stems, on twigs near nuts, and on mummies, but never on branches or leaves.

The incubation period was shortest at $27.5^{\circ} \mathrm{C}$., although eggs hatched through a temperature range of 15 to $35^{\circ} \mathrm{C}$. The rh. seemed to exert little or no effect upon incubation.

The rate of larval development appeared to be most rapid at $27.5^{\circ} \mathrm{C}$. and rh. of 75 per cent or higher. Based upon the number of larval instars, $27.5^{\circ} \mathrm{C}$. and 75 to 95 per cent rh. also appeared to approach the optimum. 
Although the navel orangeworm develops on many foods, rearings in the laboratory were confined to almond, walnut, and fresh orange. Development was most rapid on orange, but little significance should be attached to this because only two larvae were reared on orange in this study; orange, as used here, was an "unnatural" food. Development was more rapid on almond than on walnut. However, the latter might be considered a slightly more favorable food, because fewer instars were encountered and more individuals completed their development.

The seasonal population trend in the almond orchard indicated that the navel orangeworm passes the winter in the larval and pupal stages in old nuts left on the trees. From November through March, there appear to be no eggs present. First-instar larvae may be found in early winter, but are either killed or molt before late winter, as none are present during that period. Second-instar larvae are present in late winter, but by early spring they have all molted to the third instar. All other larval instars and pupae are present in the winter and early spring months. Eggs are first observed in the field in April on old stick-tight nuts hanging on the tree. The current crop becomes infested some time in August. From this time until harvest, the infestation increases.

Nuts left on the ground after harvest are probably not an important means of carrying the pest from one crop to another, because most of them are destroyed by rain, irrigation, and cultivation.

The life history on walnuts and figs is similar to that on almonds.

The navel orangeworm inflicts its damage by rasping and tunneling into the nut meats. The larvae web prolifically, and when nuts are in storage, they may move about and web several nuts together.

At the time this study was conducted, natural enemies apparently were not important in holding the navel orangeworm population below an economic level.

To date, there is no known chemical control program that is directly effective against the navel orangeworm. However, in walnuts it has been shown that good codling-moth control reduces the incidence of navel orangeworm damage.

Cultural control is the only method recommended at present. Early harvest is strongly urged. All sources of overwintering individuals should be eliminated. This means that stick-tights, nuts left lying on the ground and in the crotches of the trees, and the culls and waste products around dehydrators, hullers, and other buildings should be destroyed. If possible, these measures should be practiced on a community basis. If a crop is known to be infested, it should be fumigated immediately following harvest.

\section{ACKNOWLEDGMENTS}

The writer wishes to express his sincere appreciation to Professors O. G. Bacon and A. E. Michelbacher for their willing encouragement, assistance, and suggestions during the period of actual investigations and writing. Thanks are also due to Professors Max Gardner and E. O. Essig for advice and assistance, and to Drs. A. E. Pritchard and S. F. Bailey for identifications. 


\section{LITERATURE CITED}

Armitage, H. M.

1944. Twenty-fifth annual report, for period ending December 31, 1944. Division of Plant Industry, Bureau of Entomology and Plant Quarantine. Federal port survey. Calif. State Dept. Agr. Bul. 33(4):253.

1947. Navel orangeworm (Myelois venipars) in English walnuts. Calif. State Dept. Agr. Letter E-27, November. 2 pp.

BACON, O. G., and W. H. WADE

1954. Davis men discuss problem of navel orangeworm ravages. Almond Facts (2):7.

BAILEY, S. F.

1940. The black hunter, Leptothrips mali (Fitch). Jour. Econ. Ent. 33(3):539-43.

BisseL, T. L.

1940. Curculionidae, Bruchidae, Lepidoptera, and their parasites, infesting the seed pods of cowpea and various wild plants. Jour. Econ. Ent. 33(6):844-47.

Cockerell, T. D. A.

1899. Some insect pests of the Salt River Valley and the remedies for them. Ariz. Agr. Expt. Sta. Bul. 32:289.

Dethier, V. G.

1947. Chemical insect attractants and repellents. Blakiston Co., Philadelphia. Pages $92-$ 93,181 .

DYAR, H. G.

1890. The number of molts of lepidopterous larvae. Psyche 5(175-176):420-22.

1915. Proc. U. S. Nat. Mus. Bul. 47(2054):404.

Ebeling, W.

1959. Subtropical fruit pests. University of California, Division of Agricultural Sciences. $436 \mathrm{pp}$.

Fernald, C. H.

1892. Reports on insects. Mass. State Agr. Expt. Sta. Bul., Amherst. 19:109-143.

Gerhardt, P. D., D. L. Lindgren, and W. B. Sinclair

1951. Methyl bromide fumigation of walnuts to control two lepidopterous pests, and determination of bromine residue in walnut meats. Jour. Econ. Ent. 44(3):384-89.

1952. Fumigation of walnuts. Calif. Agr. 6(7):5.

GLICK, P. A.

1922. A survey of Myelois venipars Dyar in Arizona. Ariz. Comm. Agr. and Hort., fourteenth annual report. Pages 78-97.

1925. Proceedings of New York Entomological Society meeting of March 18, 1924. Jour. N. Y. Ent. Soc. 33:116.

Hixson, E.

1934. Myelois venipars attacking apples in Oklahoma. Jour. Econ. Ent. 27:547.

KEIFER, H. H.

1947. Annual report of the Bureau of Entomology and Plant Quarantine. Systematic entomology. Calif. State Dept. Agr. Bul. 36:168-73.

Krombein, K. V.

1954. A new Perisierola from California. Pan-Pac. Ent. 30(4):259-60.

LOCKWOOD, S.

1931. An economic survey of the navel orangeworm, Myelois venipars Dyar, in California. Calif. State Dept. Agr. Monthly Bul. 20:655-60.

MACKIE, D. B.

1942. Division of Plant Industry, Bureau of Entomology and Plant Quarantine. Systematic entomology. Calif. State Dept. Agr. Bul. 31:175.

MACKIE, D. B., and W. C. JACOBSEN

1930. Bureau of Plant Quarantine and Pest Control. Calif. State Dept. Agr. Monthly Bul. 19(12):829, 842 .

Michelbacher, A. E.

1953. Insects attacking stored products. Advances in Food Research 4:281-358. See especially: pp. 303-4. Academic Press, Inc., New York.

1956. Navel orangeworm on walnuts. Calif. Agr. 10(6):8. 
MichelbaCher, A. E., and C. S. Davis

1961. The navel orangeworm in northern California. Jour. Econ. Ent. 54(3) :559-62.

Michelbacher, A. E., and J. C. ORTEgA

1958. A technical study of insects and related pests attacking walnuts. Calif. Agr. Expt. Sta. Bul. 764:1-87.

MichelbaCher, A. E., and N. Ross

1955. Navel orangeworm. Calif. Agr. 9(3):4.

1957. Navel orangeworm. Calif. Agr. 11(7):12.

Mote, D. C.

1922. A new orange pest in Arizona. Calif. State Dept. Agr. Monthly Bul. 11:628.

ORTEGA, J. C.

1950. The navel orangeworm on walnuts in southern California. Diamond Walnut News $32(5): 6-7$.

SHARP, S. S.

1938. Important thrips in Louisiana. Proc. La. Acad. Sci. 4(1):156.

SoLOMON, M. E.

1951. Control of humidity with potassium hydroxide, sulphuric acid, or other solutions. Bul. Ent. Res. 42(3):543-54. 

The journal Hilgardia is published at irregular intervals, in volumes of about 600 pages. The number of issues per volume varies.

Subscriptions are not sold. The periodical is sent as published only to libraries, or to institutions in foreign countries having publications to offer in exchange.

You may obtain a single copy of any issue free, as long as the supply lasts; please request by volume and issue number from:

\author{
Agricultural Publications \\ Room 207 University Hall \\ 2200 University Avenue \\ Berkeley 4, California
}

The limit to nonresidents of California is 10 separate issues on a single order. A list of the issues still available will be sent on request.

In order that the information in our publications may be more intelligible it is sometimes necessary to use trade names of products or equipment rather than complicated descriptive or chemical identifications. In so doing it is unavoidable in some cases that similar products which are on the market under other trade names may not be cited. No endorsement of named products is intended nor is criticism implied of similar products which are not mentioned. 
$3)^{3}+3$

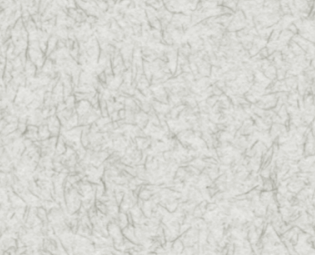

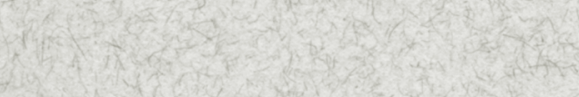
siste

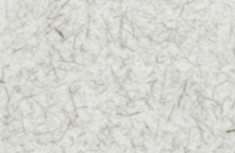

